\title{
A Numerical-Experimental Study on Orthogonal Cutting of AISI 1045 Steel and Ti6A14V Alloy: SPH and FEM Modeling with Newly Identified Friction Coefficients
}

\author{
Mohamadreza Afrasiabi ${ }^{1, *,+}\left(\mathbb{D}\right.$, Jannis Saelzer ${ }^{2,+}{ }^{\oplus}$, Sebastian Berger ${ }^{2}\left(\mathbb{D}\right.$, Ivan Iovkov ${ }^{2}\left(\mathbb{D}\right.$, Hagen Klippel ${ }^{1}(\mathbb{D}$, \\ Matthias Röthlin ${ }^{3}$, Andreas Zabel ${ }^{2}{ }^{\circledR}$, Dirk Biermann ${ }^{2}{ }^{(1)}$ and Konrad Wegener ${ }^{1}{ }^{1}$ \\ 1 Institute of Machine Tools \& Manufacturing, ETH Zürich, 8092 Zürich, Switzerland; \\ klippel@iwf.mavt.ethz.ch (H.K.); wegener@iwf.mavt.ethz.ch (K.W.) \\ 2 Institute of Machining Technology, TU Dortmund University, 44227 Dortmund, Germany; \\ jannis.saelzer@tu-dortmund.de (J.S.); sebastian.berger@tu-dortmund.de (S.B.); \\ ivan.iovkov@tu-dortmund.de (I.I.); andreas.zabel@tu-dortmund.de (A.Z.); \\ dirk.biermann@tu-dortmund.de (D.B.) \\ 3 Federal Office of Meteorology \& Climatology, MeteoSwiss, Zürich-Airport, 8058 Zürich, Switzerland; \\ matthias.roethlin@meteoswiss.ch \\ * Correspondence: afrasiabi@ethz.ch; Tel.: +41-44-632-8217 \\ + These authors contributed equally to this work.
}

Citation: Afrasiabi, M.; Saelzer, J.;

Berger, S.; Iovkov, I.; Klippel, H.;

Röthlin, M.; Zabel, A.; Biermann, D.; Wegener, K. A Numerical-

Experimental Study on Orthogonal Cutting of AISI 1045 Steel and Ti6Al4V Alloy: SPH and FEM Modeling with Newly Identified Friction Coefficients. Metals 2021, 11, 1683. https://doi.org/10.3390/ met11111683

Academic Editor: Jean-Michel Bergheau

Received: 30 September 2021

Accepted: 18 October 2021

Published: 22 October 2021

Publisher's Note: MDPI stays neutral with regard to jurisdictional claims in published maps and institutional affiliations.

Copyright: () 2021 by the authors. Licensee MDPI, Basel, Switzerland. This article is an open access article distributed under the terms and conditions of the Creative Commons Attribution (CC BY) license (https:// creativecommons.org/licenses/by/ $4.0 /)$.

\begin{abstract}
Numerical simulation of metal cutting with rigorous experimental validation is a profitable approach that facilitates process optimization and better productivity. In this work, we apply the Smoothed Particle Hydrodynamics (SPH) and Finite Element Method (FEM) to simulate the chip formation process within a thermo-mechanically coupled framework. A series of cutting experiments on two widely-used workpiece materials, i.e., AISI 1045 steel and Ti6Al4V titanium alloy, is conducted for validation purposes. Furthermore, we present a novel technique to measure the rake face temperature without manipulating the chip flow within the experimental framework, which offers a new quality of the experimental validation of thermal loads in orthogonal metal cutting. All material parameters and friction coefficients are identified in-situ, proposing new values for temperature-dependent and velocity-dependent friction coefficients of AISI 1045 and Ti6Al4V under the cutting conditions. Simulation results show that the choice of friction coefficient has a higher impact on SPH forces than FEM. Average errors of force prediction for SPH and FEM were in the range of $33 \%$ and $23 \%$, respectively. Except for the rake face temperature of Ti6Al4V, both SPH and FEM provide accurate predictions of thermal loads with $5-20 \%$ error.
\end{abstract}

Keywords: metal cutting; force; temperature; friction; simulation; FEM; SPH

\section{Introduction}

As one of the most prevalent manufacturing operations with an enormous economic impact, metal cutting has always been in the research spotlight. An in-depth physical understanding of the metal cutting process is an essential element of tool development and optimized production. With the complication of various phenomena involved in such a process, numerical simulation of metal cutting becomes an invaluable approach to develop this understanding. Nevertheless, the complex interplay between thermal and mechanical effects in metal cutting poses multiple challenges to its experimental and numerical investigation.

\subsection{General Challenges in Metal Cutting Investigation}

For the production of modern high-performance products in important industry sectors like automotive, aerospace and energy, components from different types of materials need to be provided in a sufficient quality. Two important groups of materials studied in 
this paper are medium carbon steels like AISI 1045, which can be used for a wide range of components, and titanium alloys like Ti6Al4V, which is mainly used in highly loaded lightweight applications. Machining of titanium alloys like Ti6Al4V provides two major challenges: process-vibrations which are caused by the characteristic chip segmentation [1] and high temperatures on rake face and flank face resulting in extensive tool wear [2]. To achieve a further development of tools and processes to reduce the tool wear in machining, numerical models are important resources. The state of the art already allows a good prediction of complex chip shapes [3] and the mechanical loads and their impact on tool wear [4]. However, the models are not yet qualified to achieve valid wear predictions over a broad parameter field. This applies not only to difficult-to-machine materials such as Ti6Al4V, but also to less demanding materials such as AISI 1045 [5]. Two of the challenges in valid wear prediction are the modeling of friction and the associated prediction of the temperature distribution in the tool. This paper deals with these two aspects.

The thermal load in the chip formation zone has a significant influence on the productivity of machining processes and the quality of the manufactured products. The cutting values, especially with regard to the cutting speed, are limited by the fact that the tool wear development is significantly determined by the temperature in the contact zone. On the part of the workpiece, the surface integrity is determined by the temperatures occurring during the process and their exposure times. Accordingly, for a digital design of tools and processes using chip formation models, it is necessary for the simulation systems used to reliably predict the temperatures occurring in the chip formation zone. Numerical methods are basically well suited for this purpose. However, as pointed out by Melkote et al. [6], the prediction of the tool temperature has particularly been a great challenge up to now, since this is significantly determined by the friction, which is difficult to model and necessitates a long engagement duration modeling to reach a stationary state.

Friction is the result of a complex interaction of different mechanisms, the analysis of which requires consideration at different scale levels, as Vakis et al. [7] explain in their keynote paper. In particular, Arrazola et al. [8] emphasized that the characterization and modeling of the friction mechanisms in machining remains a key challenge due to the severe conditions in the chip formation zone (which are characterized by high contact pressures, temperatures, and relative velocities) and the poor accessibility of the effective zone for metrological investigations. In this context, Zemzemi et al. [9] developed a pin-onbar tribometer which allows the measurement of the friction coefficient and the heat flux in the contact zone under conditions close to cutting with regard to the contact pressure and the temperature. With the help of the described experiment, the relative speed could be identified as the main influencing parameter on the coefficient of friction for the contact of steel material and cemented carbide. Further development of this setup was carried out by Rech et al. [10]. They used a tribometer device to investigate the influence of the relative speed on the friction coefficient for different material pairings and intermediate mediums. For all combinations investigated, the coefficient of friction decreased with increasing relative speed but depending on different boundary conditions. A plethora of empirical models, which are all based on a power function, have already described this behavior. In a more recent investigation, Meier et al. [11] conducted an in-process measurement of the friction coefficient in cutting titanium alloys and showed that the measured data is significantly affected by the tribometer setup. They proposed that choosing the most appropriate tribometer leads to values that are most representative of the situation in metal cutting.

Concerning the friction characterization, Puls et al. [12] proposed another advancement by developing a new experiment which allows the characterization of the friction stress and the coefficient of friction depending on the relative speed and the temperature under cutting conditions on a lathe with orthogonal tool engagement. Beside the boundary conditions concerning contact pressure, temperature and relative speed, the method has the main advantage compared to other tribometers for machining that the contact area can reliably be calculated due to a flat contact surface. In a second version of their experiment, 
Puls et al. [13] adopted the concept on a machine with a translational relative motion, which allows characterization in an open tribometer and, therefore, provides results which are more transferable to the conditions in the chip formation zone. Using experimental investigations and finite element simulations, Peng et al. [14] developed complex models for different materials of the coefficient of friction for chip formation simulations. This model maps the relative speed, the temperature, and the contact pressure in the secondary shear zone as influencing variables. Zanger et al. [15] investigated the influence of models for the coefficient of friction with different influencing variables. For predicting the temperatures in the chip formation zone with a finite element chip formation simulation, a friction coefficient depending on the relative speed and the normal force showed the best agreement with experimentally determined results.

For further development of the chip formation models regarding the prediction quality of the temperature distribution, the focus of the investigation is on the experiments which help to validate the models in addition to the aspects relating to the modelling itself. The temperature of the machined workpiece surface very close behind the contact to the flank face can be measured with a good precision. Therefore, the thermal impact of cutting on the workpiece surface zone can be investigated, and it is also possible to validate Finite Element chip formation simulations with respect to the workpiece temperature distribution. For example, Tapetado et al. [16] used a two-color fibre pyrometer and guided the fibre through the tool in order to measure the workpiece temperature close to the active zone. However, as Davies et al. [17] described in their related keynote paper, the key challenge is to measure the highly inaccessible contact temperatures in the secondary shear zone.

In the last two decades, some new approaches to overcome this constraint of accessibility have been developed. Al Huda et al. [18] measured the temperature of the contact side of the chip with a two-color pyrometer by guiding the pyrometer-fibre through a borehole in the tool. In a similar setup, Müller et al. [19] used a self developed two-color pyrometer which was adopted to the use in metal-cutting processes. The challenge in using this method is to position the bore for the pyrometer fibre exactly in such a way that it is above the contact zone in order to avoid blocking it with softened material of the chip and, at the same time, to move away as little as possible from the contact zone so that cooling of the chip in front of the measured point can be prevented as much as possible. For the measurement of flank face temperatures, different methods have been developed for different manufacturing processes. Dörr et al. [20] used a pyrometer to measure the flank face temperature when drilling a AISI 1045-steel. To that end, they drilled through a disk of material and positioned the pyrometer orthogonal to the surface of tool exit. With this method, they were able to identify the influence of different coatings on the temperature of the flank face at the end of the cut. Oezkaya et al. [21] used a similar approach when drilling Inconel 718 to analyze the influence of the cutting values on the temperature distribution on the flank face at different positions along the tool radius. Nishimoto et al. [22] used a partly interrupted workpiece to measure the flank face temperature in internal turning. Based on a sealed design, they could also use the system when applying a cutting fluid to the chip formation zone. In that way, the effect of a cooling and lubricating fluid on the temperature of the flank face could be investigated. The most challenging area for temperature measurements in the chip formation zone, while being the most relevant for tool and coating development, is the rake face. Due to the restricted accessibility, and the fact that the chip is moving along the rake face even in an orthogonal cutting case, the measurement of rake face temperatures in a reliable way has not been possible for a long time.

For many decades, the common way to access the temperatures on the rake face was to bring a thermocouple through a blind hole in the tool close to the rake face, so Kus et al. [23] did for hard turning of AISI 4140 to collect validation data for a finite element simulation. These methods have been used and highly developed by many researchers and are even applicable for rotating tools, as chosen by Le Coz et al. [24]. The main disadvantage of the method is that the contact zone is not reached and the spatial temperature gradients 
in the subsurface edge zone under the rake face are very large. Consequently, further developments have led to the applicant of thermocouples in tool coatings directly to the rake face. Basti et al. [25] invented built-in thin film thermocouple sensors which can be applied to cutting inserts for turning and adopted them to polycrystalline cubic boron nitride tools, which where used for the cutting of a titanium alloy. Although the processes for applying the coatings, such as those used by Li et al. [26], are constantly being further developed so that the coating process becomes more efficient and the coatings more wearresistant, this technique remains very complex. In addition, only certain coating systems can be used and an influence on the thermal properties of the tool cannot be prevented. In order to enable a measurement of the temperatures on the lateral surface of the tool, Augspurger et al. [27] used a thermographic camera. Although this strategy prevents the measurement method from influencing the temperature distribution and enables the measurement of the immediate surface temperatures, it is not possible to measure the inaccessible contact temperatures, which are much higher, like Arrazola et al. [28] could show with a new experimental setup. For this purpose, the authors clamped a workpiece with slots in the spindle of a milling machine while the tool was stationary fixed at the machine table and filmed with a thermography camera. When one of the slots reached the tool the chip formation was interrupted and the rake face became visible for a short period of time. A problem occurring during this investigation was that the chip needed to be evacuated from the rake face before an access with the camera was possible. During this time, the rake face temperature can already change. Recently, Saelzer et al. [29] developed a new method for rake face temperature measurement utilizing a two-color fibre pyrometer in orthogonal cutting by preparing the workpiece with slots. This useful approach bears only a partly interruption of the chip formation while the chip flow remains intact so that the workpiece material directly leaves the contact zone and an immediate measurement on the rake face is possible. Due to the small fibre diameter, a focused spot close to the cutting edge was also realised. This allows the measurement of the rake face temperature on a new level of accuracy, providing a new validation basis for numerical simulation of metal cutting.

\subsection{Methodological Challenges in Metal Cutting Simulation}

Generally speaking, mesh-based and particle-based techniques are the two main categories of numerical methods used for metal cutting simulations. According to an abundance of published works, the tool-of-choice in each category is the well-known Finite Element Method (FEM) and Smoothed Particle Hydrodynamics (SPH), respectively. In this context, FEM is more commonly used than $\mathrm{SPH}$ and has been in the vanguard of metal cutting models over the past few decades. This success is closely related to the ubiquity of FEM-based commercial packages in the academy and industry, but also because the numerical algorithms in FEM developments have reached maturity. In particular, the number and quality of published works based on a Lagrangian formulation of FEM are remarkable. The main technical disadvantage of such models, however, lies in the mesh recomputation, which is a cumbersome procedure required for the solution stability and mesh distortion issues. In other words, the main issue with the application of (Lagrangian) FEM solvers to cutting problems is this re-meshing procedure that brings numerical inaccuracy while entailing high computational costs. A good overview of some notable accounts in the FEM modeling of machining processes can be found in [8]. More recently, Childs et al. [30] applied a thermo-elasto-plastic Lagrangian FEM code to Ti6Al4V chip formation simulation using a modified failure model and claimed satisfactory agreement between the model and experiments. They investigated the chip geometry, process forces and tool temperatures over a wide range of cutting speed ranging from 1 to $100 \mathrm{~m} / \mathrm{min}$. However, validation of chip temperatures is lacking in their work.

As a relatively younger approach than FEM, SPH has received much attention from the cutting simulation community due to its unique capabilities in handling large deformation and material separation problems. In an early effort, Limido et al. [31] developed an 
LS-DYNA ${ }^{\circledR}$ SPH model of high-speed cutting and compared the predicted cutting forces and chip morphology against the experimental data. This pioneering work revealed the great potentials of SPH in more advanced cutting simulations; nevertheless, it lacks a full thermomechanical coupling by ignoring to solve the heat equation. Ruttimann et al. [32] published the first SPH work, in which a 3D cutting test was verified experimentally. They demonstrated that the computational time of an SPH single-grain model is only a fraction of what FEM needs for a comparable result. Madaj and Piŝka [33] simulated the orthogonal cutting of an aluminum alloy and validated the chip shapes, von Mises stress, plastic strains, strain rates, and cutting forces obtained from SPH with other published results. They concluded that the size of SPH particles plays a key role in resolving segmented chip shapes. In order to address the high computational cost of SPH cutting simulations, Spreng et al. [34] developed the first adaptive framework for meshfree metal cutting problems and showcased their development in a 2D orthogonal test. Afrasiabi et al. [35] carried out a more detailed study on the runtime optimization of SPH cutting simulations and by focusing on the interplay between the discretization effects and the accuracy of Ti6Al4V chip serration. They published the first open-source multi-resolution SPH code for metal cutting, realizing that more than $50-70 \%$ of the SPH calculation time can be saved via dynamic particle refinement. Niu et al. [36] addressed another deficiency of SPH regarding its kernel inconsistency. They corrected the density approximation by a more accurate $\mathrm{SPH}$ kernel function and showed that chip formation using an improved kernel is more accurate.

It would not be until only a few years ago that the SPH cutting models could take a major leap forward in their proficiency. Roethlin et al. [37] accelerated the runtime of $\mathrm{SPH}$ cutting simulations dramatically via GPU parallel computing. As a result of very short evaluation cycles, the authors performed several parameter studies on the effects of cutting parameters and displayed ultra-fine discretization in SPH cutting simulations. These authors extended their code in [38] to a 3D single-grain grinding experiment, where the presented SPH results are believed to be the most high-resolution $3 \mathrm{D}$ metal cutting simulation to date. Within a numerical-experimental framework, Afrasiabi et al. [39] focused on the influence of friction modeling on the accuracy of force prediction and proposed the first temperature-dependent friction model for SPH metal cutting through an inverse identification method. They found that employing an enhanced friction coefficient can reduce the usual inaccuracy of passive force prediction significantly.

While all these publications have made crucial steps in the maturity of SPH metal cutting models, friction and material parameters in almost all of them are assumed from other work. More importantly, none of these papers provides experimental validation of thermal loads. Although Afrasiabi et al. [40] have recently taken the first step to fill this gap, there are some issues in their results that still need to be addressed. Firstly, the experimental validation of thermal loads was adapted from other work and reported only for the rake face temperature. Secondly, the simulation results presented in [40] are low resolution (as the SPH runtime is not accelerated) and taken only after a cut distance of $0.3 \mathrm{~mm}$, which seems insufficient to establish a steady-state temperature distribution. The very recent publication of [41] addresses these issues and presents a complete thermal model for metal cutting simulation.

\subsection{Present Work}

The presented literature review revealed that so far no reliable method for temperature measurements at the rake face has been used for validating chip formation simulations. The experimental method described in [29] provides new possibilities for this purpose. However, a method must be developed for transferring the experimentally determined values to the chip formation simulations. Furthermore, it appears that the current state of SPH cutting simulations is still not as well-established as FEM in terms of performance and material-friction data, thus needing further investigation. Bridging these knowledge gaps motivates this study to offer a systematic numerical-experimental approach (see Table 1). In summary, the novelty and/or comprehensiveness of this work lie in: 
- Numerical simulation of metal cutting with both FEM and SPH

- New quality of experimental validation of thermal loads

- Identification of friction and flow stress parameters for AISI 1045 and Ti6Al4V

- Proposing new values for temperature- and velocity-dependent friction coefficients in metal cutting

The manuscript is organized as follows. In Section 2, the experimentation is described in some detail, including the setup and methodologies used for force and temperature measurements. Section 3 presents the simulation framework for metal cutting problems with SPH and FEM. As the core of this paper, Section 4 presents the numerical results alongside a series of experimental validation by means of force and temperature measurements. Finally, the paper closes by summarizing the key findings of this research and discussing some opportunities for further improvements, given in Section 5.

Table 1. Overview of the main research gaps identified in Sections 1.1 and 1.2 and the approach proposed in this paper to fill them.

\begin{tabular}{ll}
\hline Issues with Current Models & Proposed Approach \\
\hline $\begin{array}{l}\text { No experimental validation of simulated temperatures in } \\
\text { metal cutting }\end{array}$ & $\begin{array}{l}\text { A new strategy for rake face temperature measurement to } \\
\text { generate validation data. }\end{array}$ \\
\hline $\begin{array}{l}\text { Friction modeling approaches in SPH cutting simulations do not } \\
\text { include the effect of relative velocity }\end{array}$ & $\begin{array}{l}\text { Identification of different friction coefficients and performing } \\
\text { sensitivity analyses to quantify their effects. }\end{array}$ \\
\hline $\begin{array}{l}\text { No rigorous comparison of FEM and SPH in metal cutting } \\
\text { simulations within a unified constitutive modeling framework. }\end{array}$ & $\begin{array}{l}\text { Unification of both methods concerning the constitutive models } \\
\text { with the newly determined parameters. }\end{array}$ \\
\hline
\end{tabular}

\section{Experimental Investigation}

In this section, the experimental framework utilized to validate the numerical simulations is described. The process definitions and details of the cutting tests are presented, followed by an explanation of the measurement procedure for forces and temperature.

\subsection{Experimental Setup}

Within the framework of the experimental investigation, orthogonal cutting was performed on a special machine for chip formation analysis (Figure 1). This machine, which is based on a gantry-type milling machine, consists of a table with a linear direct drive and a traverse with two additional axes. The cutting motion with cutting speeds up to $v_{c}=180 \mathrm{~m} / \mathrm{min}$ is obtained using the linear direct drive, while the table is carrying the workpiece, which has a width of $w=2 \mathrm{~mm}$ and a length of $l=140 \mathrm{~mm}$. At the traverse, the tool is attached and therefore positioned by the two axes in a defined relative position to the workpiece in order to control the cross-section of undeformed chips. Due to the fact that the passive force is primarily determined by the friction between the chip and the rake face, the rake angle was set to $\gamma=0^{\circ}$ and a comparatively large clearance angle of $\alpha=10^{\circ}$ was chosen. The cutting edge radius, which was measured with the help of a focus variation microscope, amounts to $r_{\beta}=10 \mu \mathrm{m}$ in all cases.

In this study, two different materials were investigated. The first was AISI 1045 in a normalized heat treatment condition, which is commonly used for various automotive power-train components with a hardness of $167 \mathrm{HV} 2$. Second, the titanium alloy Ti6Al4V, which is widely used in the aerospace industry and has a hardness of 330 HV2. For both materials the cutting speed and the uncut chip thickness were varied on three levels, with a range of values given in Tables 2 and 3 at the end of this section. For the AISI 1045 steel the upper boundary for the cutting speed is defined by the machine side restriction of $v_{c}=180 \mathrm{~m} / \mathrm{min}$. The lowest cutting speed is chosen so that a comparison with Ti6Al4V is possible. For this material $v_{c}=60 \mathrm{~m} / \mathrm{min}$ is in the extent of the maximum which is reached in the industry. Below these limits, two cutting speeds were selected in each case. The values of the chip thickness correspond to a realistic level for turning operations. 

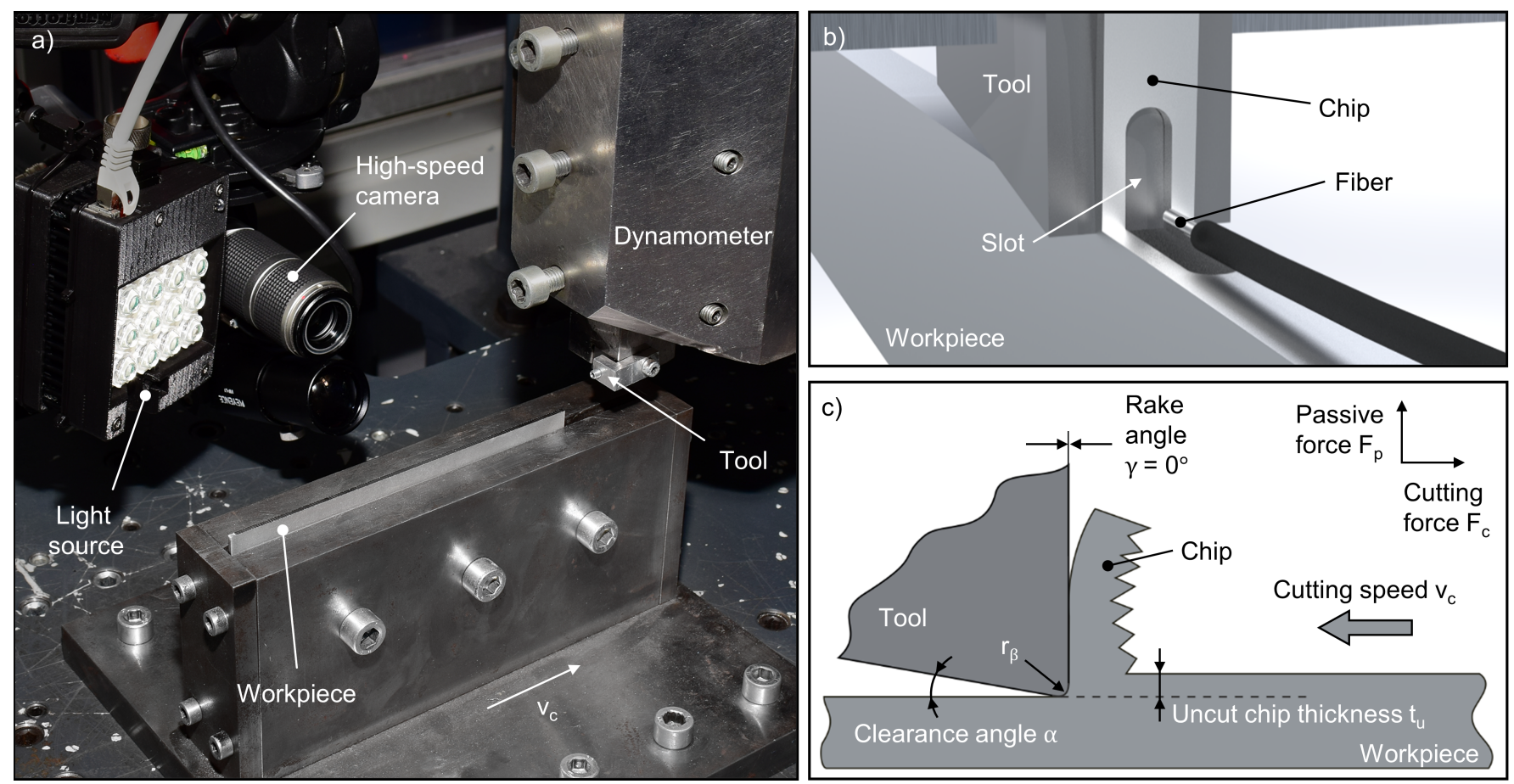

Figure 1. Orthogonal cutting tests. (a) Experimental setup with measurement devices; (b) Principle of rake face temperature measurement; (c) Schematic illustration of the orthogonal cutting process.

\subsection{Force and Temperature Measurements}

To measure the cutting and passives forces in the process, a dynamometer type 9263 from Kistler Instrumente AG was used. A sampling rate of $f_{F}=100 \mathrm{kHz}$ was applied to capture the characteristics of the chip formation within the force measurement. For each cut, the two force components were evaluated in the stationary area and the values there averaged.

In the course of the investigations, the temperature on the free chip surface, as well as the temperature on the rake face in the vicinity of the cutting edge, were measured using the two-color fiber pyrometer Fire-III from en2Aix-energy engineering Aachen GmbH. In particular, an innovative methodology was developed to measure the rake face temperature. This new technique provides accessibility of the rake face while maintaining chip flow by temporarily and locally interrupting chip formation. For this purpose, slots in cutting direction are inserted into the workpiece. Thus, initially there is a stationary full cut to reach a steady temperature on the rake face. During this period the temperature of the free chip surface can be measured. Once the tool reaches the slot, it is transferred to the chip and thereby the center of the rake face is temporarily made accessible for measurement. Because the cut is not completely interrupted, the chip flow is maintained, which means that the measurement is unaffected by falling chips. For additional details of the experimental setup, please refer to [29] and Figure 1. Using a fixture, the fiber with a diameter of $d_{f}-330 \mu \mathrm{m}$ was orthogonally positioned close to the cutting zone, so that a measuring spot diameter of $d_{M P}=0.9 \mathrm{~mm}$ could be set on the chip and of $d_{M P}=1.2 \mathrm{~mm}$ on the tool. The sampling rate was set to $f_{T}=25 \mathrm{kHz}$. According to the measuring principle of the pyrometer, the temperature in the area of the measuring spot was averaged. As representative for a cutting test, the arithmetic mean value is calculated in the steady-state of the temperature measurement signal. The uncertainty of measurement given by the manufacturer of the pyrometer is $15 \mathrm{~K}$. In the course of preliminary investigations on a calibration furnace with a homogeneously distributed temperature of $T_{r e f}=573 \mathrm{~K}$ the difference between set temperature and measured temperature was less then $1 \%$. 
A full list of cutting parameters together with the force and temperature measurements are presented in Tables 2 and 3 . Throughout this manuscript, the free chip surface and rake face temperatures are abbreviated to $T_{F C S}$ and $T_{R F}$, respectively.

Given the experimentally measured forces, and because the rake angle is $\gamma=0^{\circ}$ for all cases, the apparent coefficient of friction can be easily calculated via $\mu=F_{p} / F_{c}$. Nine coefficients of friction are available for each material according to the variation of $t_{u}$ and $v_{c}$. Figure 2 plots these data points. With a few exceptions, it can be stated with regard to the forces that they decrease with increasing cutting speed due to thermal softening. In cases where this is not found to be the rule, a change in the adhesion behavior due to the cutting speed is assumed. At low chip thicknesses, the coefficient of friction increases despite an overall decrease in forces. This is due to the fact that the cutting force, which is mainly determined by material deformation in the primary shear zone, is reduced to a greater extent by thermal softening than the passive force, which is mainly caused by friction. Moreover, the diagram shows that the average coefficient of friction for AISI 1045 is $\bar{\mu}=0.738$, which is $40 \%$ larger than $\bar{\mu}=0.541$ for Ti6Al4V. The maximum value of $\mu$ in both cases was found at the smallest uncut chip thickness and highest cutting speed. For the machining of Ti6Al4V, distinct adhesion to the tools occurs, especially at the low and medium cutting speeds. This suggests that there is no direct contact between the tool and the out-flowing material during the cutting process, but rather the material slides off on itself after an initial buildup of adhesion, which can explain the overall lower level of the coefficient of friction compared to AISI 1045. In the case of AISI 1045, very flat, bluish discolored adhesion appears at high cutting speeds, indicating a partially liquefied intermediate layer. Accordingly, lower coefficients of friction occur in this area.

Table 2. Cutting experiments data for AISI 1045.

\begin{tabular}{|c|c|c|c|c|c|c|c|c|c|c|}
\hline Case & $v_{c}(\mathrm{~m} / \mathrm{min})$ & $t_{u}(\mathrm{~mm})$ & $\gamma^{\circ}$ & $\alpha^{\circ}$ & $r_{\beta}(\mu \mathrm{m})$ & $F_{c}(\mathrm{~N})$ & $F_{p}(\mathrm{~N})$ & $\mu=F_{p} / F_{c}$ & $T_{R F}(\mathrm{~K})$ & $T_{F C S}(\mathbf{K})$ \\
\hline 1 & \multirow{3}{*}{60} & 0.10 & \multirow{3}{*}{0} & \multirow{3}{*}{10} & \multirow{3}{*}{10} & 622 & 489 & 0.786 & 668 & 647 \\
\hline 2 & & 0.15 & & & & 833 & 637 & 0.765 & 730 & 639 \\
\hline 3 & & 0.20 & & & & 1022 & 802 & 0.785 & 732 & 643 \\
\hline 4 & \multirow{3}{*}{120} & 0.10 & \multirow{3}{*}{0} & \multirow{3}{*}{10} & \multirow{3}{*}{10} & 492 & 404 & 0.821 & 795 & 671 \\
\hline 5 & & 0.15 & & & & 735 & 557 & 0.758 & 893 & 657 \\
\hline 6 & & 0.20 & & & & 944 & 670 & 0.710 & 995 & 649 \\
\hline 7 & \multirow{3}{*}{180} & 0.10 & \multirow{3}{*}{0} & \multirow{3}{*}{10} & \multirow{3}{*}{10} & 526 & 436 & 0.829 & 925 & 678 \\
\hline 8 & & 0.15 & & & & 746 & 530 & 0.710 & 1031 & 658 \\
\hline 9 & & 0.20 & & & & 900 & 583 & 0.648 & 1102 & 658 \\
\hline
\end{tabular}

Table 3. Cutting experiments data for Ti6Al4V.

\begin{tabular}{|c|c|c|c|c|c|c|c|c|c|c|}
\hline Case & $v_{c}(\mathrm{~m} / \mathrm{min})$ & $t_{u}(\mathrm{~mm})$ & $\gamma^{\circ}$ & $\alpha^{\circ}$ & $r_{\beta}(\mu \mathrm{m})$ & $F_{c}(\mathrm{~N})$ & $F_{p}(\mathrm{~N})$ & $\mu=F_{p} / F_{c}$ & $T_{R F}(\mathrm{~K})$ & $T_{F C S}(\mathrm{~K})$ \\
\hline 10 & & 0.10 & & & & 597 & 303 & 0.507 & 701 & 711 \\
\hline 11 & 20 & 0.15 & 0 & 10 & 10 & 629 & 356 & 0.566 & 690 & 687 \\
\hline 12 & & 0.20 & & & & 748 & 339 & 0.453 & 771 & 667 \\
\hline 13 & & 0.10 & & & & 434 & 256 & 0.590 & 783 & 688 \\
\hline 14 & 40 & 0.15 & 0 & 10 & 10 & 602 & 337 & 0.560 & 873 & 665 \\
\hline 15 & & 0.20 & & & & 728 & 367 & 0.504 & 900 & 668 \\
\hline 16 & & 0.10 & & & & 412 & 259 & 0.629 & 918 & 692 \\
\hline 17 & 60 & 0.15 & 0 & 10 & 10 & 581 & 336 & 0.578 & 965 & 690 \\
\hline 18 & & 0.20 & & & & 680 & 346 & 0.509 & 998 & 728 \\
\hline
\end{tabular}




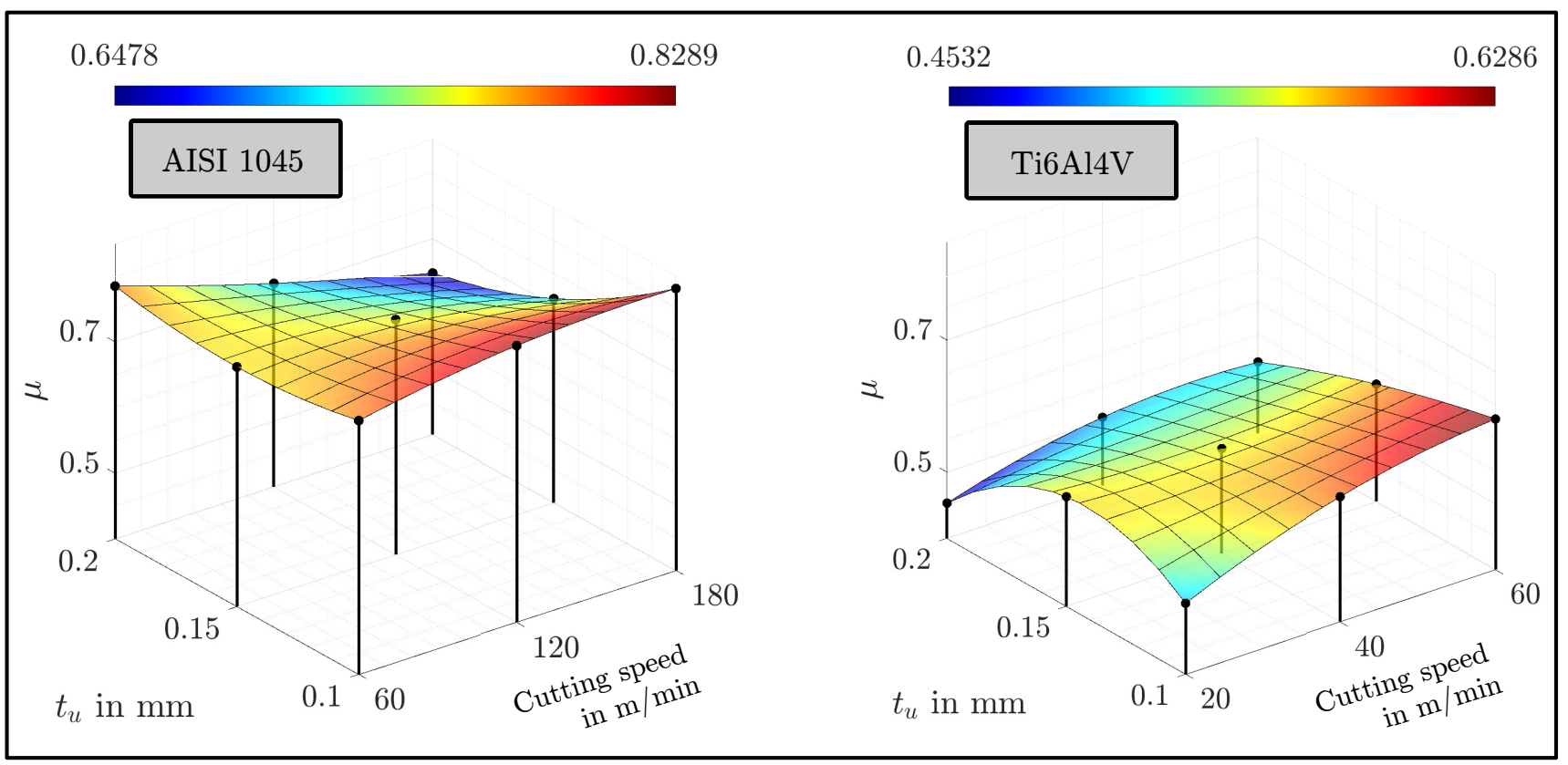

Figure 2. Apparent coefficients of friction as $\mu=F_{p} / F_{c}$ calculated directly from the measured forces given in Tables 2 and 3.

\section{Numerical Simulation Framework}

For simulating a metal cutting process, the computational model involves a broad range of thermal, mechanical, and material effects. After summarizing these thermalmechanical-material equations from a theoretical perspective, this section provides an overview of some details regarding the numerical simulation of metal cutting with FEM and SPH. Regarding the thermal boundary conditions in these simulations, a Dirichlet temperature boundary condition of $T=293 \mathrm{~K}$ was imposed on the fixed surfaces. Additionally, a Neumann boundary condition was imposed on the open surfaces with radiation and convection modeled through heat loss terms-see $q_{l}$ in Equation (6). Figure 3 illustrates this setup together with the mechanical boundary condition, where the bottom of the workpiece is clamped vertically.

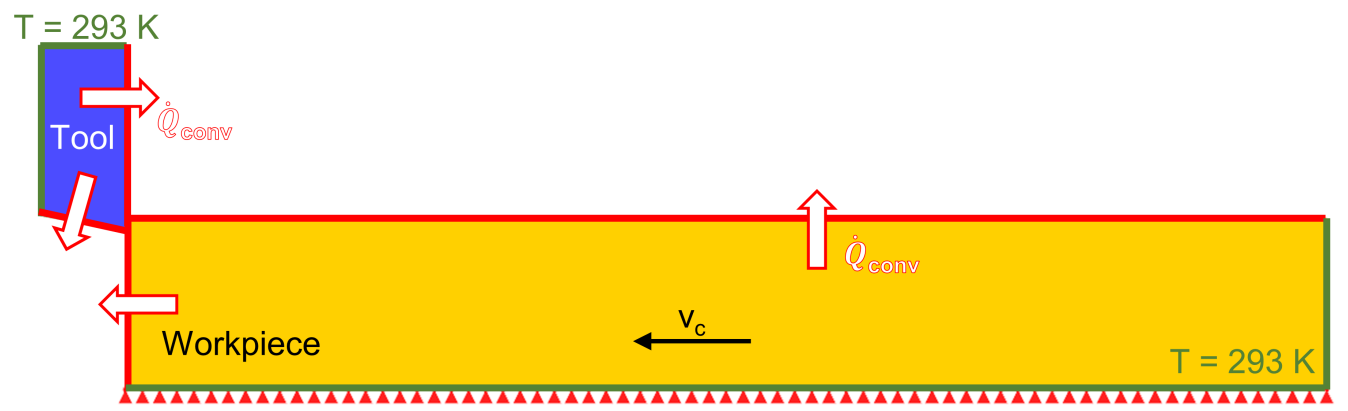

Figure 3. Thermomechanical boundary conditions for the FEM and SPH metal cutting simulations.

\subsection{Governing Equations}

The governing equations for a thermo-mechanically coupled analysis of metal cutting in the Lagrangian frame of reference read: 


$$
\begin{aligned}
\frac{d \rho}{d t} & =-\rho \nabla \cdot \underline{v} \\
\rho \frac{d \underline{v}}{d t} & =\nabla \cdot \underline{\underline{\sigma}}+\underline{b} \\
\rho c_{p} \frac{d T}{d t} & =k \nabla^{2} T+Q_{s} \\
\frac{d \underline{r}}{d t} & =\underline{v}
\end{aligned}
$$

where $\rho$ is the density, $\underline{v}$ the velocity vector, $\underline{\underline{\sigma}}$ the Cauchy stress tensor, $\underline{b}$ the volumetric body forces, $c_{p}$ the specific isobaric heat capacity, $T$ the temperature, $k$ the heat conductivity assuming an isotropic material, and $\underline{r}$ the position vector. The term $Q_{s}$ represents some volumetric heat source(s), which in metal cutting, according to [42], can be calculated from:

$$
Q_{s}=\chi\left(\sigma_{y} \dot{\bar{\varepsilon}}^{p l}\right)+\eta\left(\frac{\rho\left|\underline{f}^{\mathrm{fric}}\right| \cdot\left|\underline{v}^{\mathrm{rel}}\right|}{m}\right)
$$

where $\eta$ and $\chi$ are dimensionless parameters between 0 and 1 , specifying how much of the plastic and frictional work is turned into heat, $\sigma_{y}$ is the effective flow stress of the material, $\dot{\bar{\varepsilon}}^{p l}$ the equivalent plastic strain rate, and $\left|f^{\text {fric }}\right|$ the magnitude of friction force. This expression indicates that the plastic deformation work, as well as the frictional contact, are the main sources of heat generation in metal cutting. The boundary conditions associated with Equation (3) include the Dirichlet and Neumann boundary conditions, where heat loss, $q_{l}$, occurs via radiation and convection through open surfaces:

$$
q_{l}=-\left[h_{c}\left(T_{s}-T_{\infty}\right)+\epsilon \sigma\left(T_{s}^{4}-T_{\infty}^{4}\right)\right]
$$

in which $h_{c}$ is the heat convection coefficient, $T_{s}$ and $T_{\infty}$ the surface and background temperatures, $\epsilon$ the emissivity factor, and $\sigma$ the Stefan-Boltzmann constant. Because of the important role played by the flow stress and friction in metal cutting problems, these two topics are elaborated separately in the subsequent sections.

\subsubsection{Flow Stress Modeling}

As the most commonly-used choice for metal cutting models, the Johnson-Cook (JC) flow stress by [43] is used to define the plastic response of the workpiece material. This model calculates the flow stress of the material $\sigma_{y}$ by accounting for strain hardening, strain rate hardening, and thermal softening effects. The JC flow stress is computed from:

$$
\sigma_{y}^{\mathrm{JC}}= \begin{cases}{\left[A+B\left(\bar{\varepsilon}^{p l}\right)^{n}\right]\left[1+C \ln \left(\frac{\dot{\bar{\varepsilon}}^{p l}}{\dot{\bar{\varepsilon}}_{0}^{p l}}\right)\right]\left[1-\left(\frac{T-T_{r}}{T_{m}-T_{r}}\right)^{m}\right]} & \text { if } \varepsilon \leq 2 \\ 1133.92\left[1+C \ln \left(\frac{\dot{\bar{\varepsilon}}^{p l}}{\dot{\bar{\varepsilon}}_{0}^{p l}}\right)\right]\left[1-\left(\frac{T-T_{r}}{T_{m}-T_{r}}\right)^{m}\right] & \text { if } \varepsilon>2\end{cases}
$$

where $\bar{\varepsilon}^{p l}$ is the equivalent plastic strain and $T_{r}$ and $T_{m}$ are the reference temperature and melting point, respectively. In this work, the values of five JC parameters $(A, B, C, m$ and $n$ ) are determined by a series of Split-Hopkinson-Pressure-Bar tests (SHPB), provided in Table 4. This is a method for highly dynamic flow stress characterization, in which the sample is compressed by a pneumatically generated pulse at strain rates of up to $\dot{\varepsilon}=10000 \mathrm{~s}^{-1}$. Unlike other methods for flow stress characterization, this allows the 
dynamic material hardening to be quantified. With the help of an inductive heater, the initial sample temperature could also be varied between room temperature and $T=1023 \mathrm{~K}$ and thus the influence of thermal softening on the flow stress could be recorded. This covers a significant part of the temperature interval occurring in the chip formation zone. The experimental setup and the evaluation of the data are described in [44] with more details.

Table 4. Johnson-Cook parameters identified for AISI 1045 and Ti6Al4V.

\begin{tabular}{|c|c|c|c|c|c|c|c|c|}
\hline \multirow[b]{2}{*}{ Material } & \multirow[b]{2}{*}{$A$ (MPa) } & \multirow[b]{2}{*}{$B$ (MPa) } & \multirow[b]{2}{*}{$C(-)$} & \multirow[b]{2}{*}{$m(-)$} & \multirow[b]{2}{*}{$n(-)$} & \multicolumn{3}{|c|}{ SHPB Testing Conditions } \\
\hline & & & & & & $\varepsilon_{0}(-)$ & $\dot{\varepsilon}_{\max }(1 / \mathrm{s})$ & $T_{\max }(\mathrm{K})$ \\
\hline AISI 1045 & 288 & 695 & 0.0340 & 1.3558 & 0.2835 & 0.004 & 5834 & 1023 \\
\hline Ti6Al4V & 940 & 965 & 0.0387 & 0.9835 & 0.8372 & 0.004 & 5638 & 1023 \\
\hline
\end{tabular}

The Johnson-Cook model predicts higher and higher flow stresses for increasing strains. However, this does not usually apply to the work hardening of steel materials. Starting from a strain of approximately $\varepsilon=2$, the formation of new dislocations and the mutual extinction of existing dislocations remain in a state of equilibrium as deformation progresses. Consequently, the flow stress in this strain range approaches a limit value and remains at a constant level beyond that, as it was proven by [45]. For AISI 1045 the finite element simulations overestimate the forces, when the flow stress is calculated with the Johnson-Cook model. Thereforein part of the simulations, an alternative model will be investigated for mapping the flow stress behavior of AISI 1045 in that way. For this purpose, the flow stress model is defined in sections, where for $\varepsilon \leq 2$ it corresponds to the first expression in Equation (7), which corresponds to the standard form of the J-C model and for $\varepsilon>2$ the strain hardening term is set constant to the value which it takes at a strain of $\varepsilon=2$, i.e., $1133.92 \mathrm{MPa}$, as can be seen in the second expression in Equation (7). This formulation is independent from the level of strain-rate and temperature. The sectionally-defined model is referred to as the modified Johnson-Cook model throughout this paper.

\subsubsection{Friction Modeling}

In this paper, $f^{\text {fric }}$ is the force of friction approximated by Coulomb's law at all toolworkpiece contact surfaces:

$$
\left|\underline{f}^{\text {fric }}\right|=\mu(\zeta)\left|\underline{f}^{\text {cont }}\right|
$$

where $f^{\text {cont }}$ is the (normal) contact force between the tool and workpiece, and $\zeta$ a state variable. In addition to a prescribed constant value, the coefficient $\mu(\zeta)$ of friction is taken here to be either temperature-dependent $\mu(T)$ or relative-velocity-dependent $\mu(v)$. This consideration is motivated by the fact that the contact temperature and sliding velocity play an important role in frictional conditions at the tool-chip interface. Instead of including these two effects simultaneously and describing the friction coefficient as a function of temperature and velocity as $\mu(T, v)$, the effects of these parameters and their impact on the accuracy of the simulation results are compared separately in this work. Note that the symbol $v$ indicates the relative speed for brevity, whereas the cutting speed is denoted by $v_{c}$ throughout this manuscript.

For identifying a velocity-dependent friction coefficient, experiments were conducted to characterize friction under conditions similar to machining. For this purpose, a carbide body and a workpiece are brought into contact and moved relative to each other at a defined length and an angle of $5^{\circ}$. The relative speed is varied between $v=10 \mathrm{~m} / \mathrm{min}$ and $v=180 \mathrm{~m} / \mathrm{min}$. The experimental principle was first introduced by [13] for three metallic materials; however, the procedure in this work follows the data documented by [46]. Due to the changing intensity of the friction mechanisms over the relative speed, the behavior of AISI 1045 cannot be described by a single function; therefore, it is defined 
in two sections to account for the physics of the characterization test (Table 5 and Figure 4). For low relative speeds, the contact is dominated by adhesion and the coefficient of friction is independent of the relative speed. From a relative speed of $v=46 \mathrm{~m} / \mathrm{min}$ on, the tendency to work-hardening decreases, so that the adhesion and buildup edge generation decreases and more abrasive contact occurs. With increasing relative speed, which entails a higher temperature, the coefficient of friction decreases because the abrasive friction components run under lower resistance with further increasing temperature. At very high relative speeds, a partially fluid intermediate layer forms and the coefficient of friction remains at an almost constant level.

After the constant and velocity-dependent coefficient of friction, the third type of $\mu$ considered here is sensitive to the temperature of the contacting surfaces, i.e., $\mu(T)$. Similar to the thermal softening term of the JC flow stress model, the behavior of $\mu(T)$ is expressed by an exponential decay as:

$$
\mu(T)=\mu_{0}\left[1-\left(\frac{T-T_{r}}{T_{m}-T_{r}}\right)^{q}\right]
$$

where $\mu_{0}$ and $q$ are the unknown coefficients of the system. Identification of these two parameters are performed by following the same procedure as described by [39,47] in detail, where the unknown constants are determined through a force optimization scheme with an inverse method. For this purpose, efficient SPH simulation of metal cutting is carried out using the open-source code mfree-iwf with variable input parameters.

Table 5. Proposed coefficients of friction (CoF) for AISI 1045 and Ti6Al4V.

\begin{tabular}{|c|c|c|c|}
\hline Material & Temperatu & re-Dependent CoF & Velocity-Dependent CoF $(v)=\mathrm{m} / \mathrm{min}$ \\
\hline AISI 1045 & $\mu(T)=0.81$ & {$\left[1-\left(\frac{T-T_{r}}{T_{m}-T_{r}}\right)^{2.09}\right]$} & $\mu(v)= \begin{cases}0.622 & |v|<46 \mathrm{~m} / \mathrm{min} \\
\mu(v)=5.14|v|^{-0.53} & |v| \geq 46 \mathrm{~m} / \mathrm{min}\end{cases}$ \\
\hline Ti6Al4V & $\mu(T)=0.51$ & {$\left[1-\left(\frac{T-T_{r}}{T_{m}-T_{r}}\right)^{5.76}\right]$} & $\mu(v)=0.627|v|^{-0.154}$ \\
\hline
\end{tabular}

For each material, the test case related to the median value of the cutting speed and uncut chip-thickness is considered. As such, the experimental data set for parameter identification of $\mu(T)$ pertains to $v_{c}=120 \mathrm{~m} / \mathrm{min}$ and $t_{u}=0.15 \mathrm{~mm}$ in the case of AISI 1045 , and $v_{c}=40 \mathrm{~m} / \mathrm{min}$ and $t_{u}=0.15 \mathrm{~mm}$ in the case of Ti6Al4V. The best combination of $\mu_{0}$ and $q$ is then found by minimizing the prediction error between the numerical simulation and experimental measurement of the process forces. Similar to the optimization criterion used by [39], the inverse identification algorithm minimizes the approximation error of both $F_{c}$ and $F_{p}$ simultaneously. Table 5 shows the identified parameters of $\mu(T)$ and $\mu(v)$, summarizing the proposed friction coefficients for orthogonal cutting of AISI 1045 and Ti6Al4V. These four functions are plotted in Figure 4. Technically, this procedure needs to be repeated for all 18 cases listed in Tables 2 and 3. Nevertheless, the coefficients shown in Table 5 are used as an approximation for each material in this paper. 

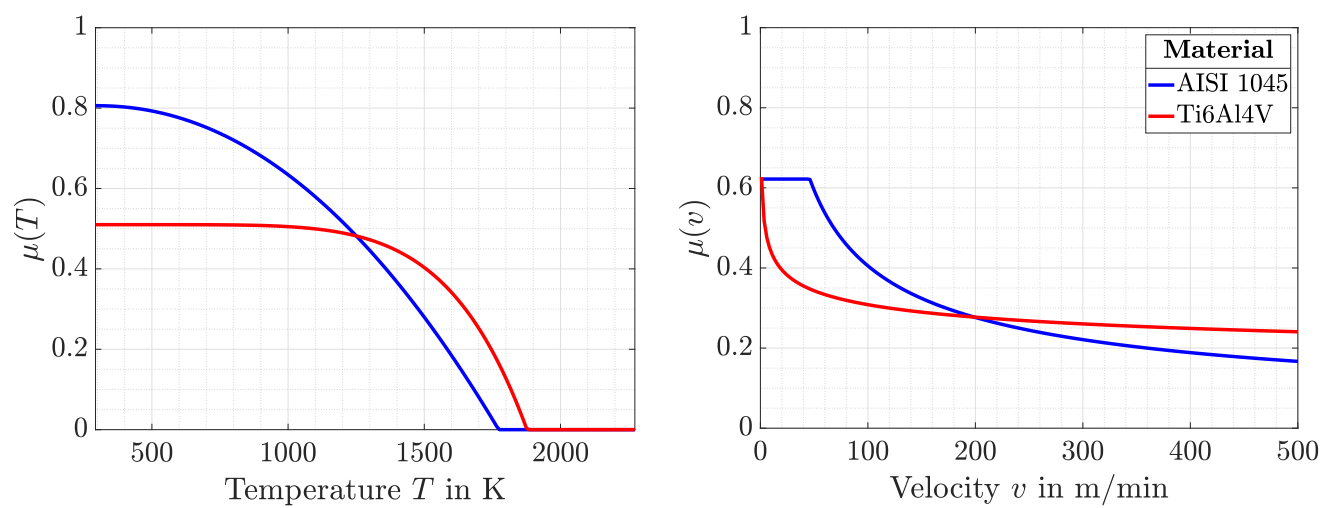

Figure 4. Proposed friction coefficients as a function of: (Left) temperature; (Right) relative velocity.

\subsection{Finite Element Modeling}

A Finite Element (FE) chip formation simulation was carried out using the commercial package DEFORM2D ${ }^{\circledR}$ v12.0. This FE-based solver implements the Lagrangian formulation, and is well known as a powerful simulation tool for analyzing cutting processes and metal forming as well. Table 6 gives an overview of the boundary conditions of the finite element simulation model, which is detailed described in the following section. The software has an automatic remeshing routine, which allows efficient calculations of manufacturing processes with high strains and strain rates of the workpiece material, as it is the case in machining. Moreover, DEFORM provides an integrated chip separation criterion which allows to predict the chip formation within the Lagrangian formulation. The simulations were carried out with the multifrontal-massively-parallel-sparse-direct-solver and the Newton-Raphson iteration method. This combination provides low computational times compared to others. However, the calculation time is also influenced by other factors such as the selected friction model as well as the material and varies as a result, as can be seen in the table. In order to be able to investigate a broad experimental plan with different cutting conditions and friction models the simulations were all performed in $2 \mathrm{D}$ with a plane strain assumption. This assumption is suitable because the side flow of the chip can be ignored in the 2D-simulation.

Table 6. Boundary conditions of the finite element simulation.

\begin{tabular}{ll}
\hline Boundary Condition & \\
\hline Formulation & Lagrangian \\
\hline Solver & Multifrontal-massively-parallel-sparse-direct \\
\hline Iteration method & Newton-Raphson \\
\hline Type of elements & Quadrilateral \\
\hline Geometry type & Plane strain \\
\hline Elements along uncut chip thickness & 20 \\
\hline Used processor & Intel(R) Xeon $(\mathrm{R}) \mathrm{CPU}$ E3-1225 v5 3.30GHz \\
\hline Step increment & $1.41 \times 10^{-5} \mathrm{~s} /$ step \\
\hline Computing time for 1000 steps & 6 to $15 \mathrm{~h}$ \\
\hline & Cutting force \\
Calculated Parameters & Passive force \\
& Temperature of free chip surface \\
\end{tabular}

In Table 7, the thermomechanical properties of the carbide tool and workpiece materials, taken from the DEFORM2D ${ }^{\circledR}$ database, are shown. 
Table 7. Material properties of the carbide cutting tool.

\begin{tabular}{llcll}
\hline Body & Property & Symbol & Unit & Value \\
\hline \multirow{3}{*}{ Tool } & Density & $\rho$ & $\mathrm{kg} / \mathrm{m}^{3}$ & 15,700 \\
& Heat conductivity & $k$ & $\mathrm{~W} /(\mathrm{m} \mathrm{K})$ & 59 \\
& Specific heat capacity & $c_{p}$ & $\mathrm{~J} /(\mathrm{kg} \mathrm{K})$ & 15 \\
\hline \multirow{3}{*}{ Surfaces } & Convection coefficient & $h_{c}$ & $\mathrm{~W} /\left(\mathrm{m}^{2} \mathrm{~K}\right)$ & 45 \\
& Stefan-Boltzmann constant & $\sigma$ & $\mathrm{W} /\left(\mathrm{m}^{2} \mathrm{~K}^{4}\right)$ & $5.67 \times 10^{-8}$ \\
& Emissivity coefficient & $\epsilon$ & - & 0.4 \\
\hline
\end{tabular}

To model the flow stress of the workpiece and the friction behavior between tool and workpiece as well as between tool and chip, the models explained in the previous subsections are used. The workpiece was modeled as plastic, whereby a thermo-plastic coupling is provided by the FE code. With regard to the tool, the assumption was made that it behaves rigidly. For the discretization of the tool and workpiece, a graded meshing with quadrilateral elements was chosen, which provides smaller element size in areas with high gradients of the state variables in order to increase the accuracy of the results and, in the case of Ti6 Al4V, to be able to map the chip segmentation. In preliminary investigations, it was determined that for 15 or more elements over the uncut chip thickness, the results of the simulation depend only to a small extent on the mesh density. Accordingly, the element length of the workpiece in the region of the primary and secondary shear zones was set to one-twentieth of the uncut chip thickness. Outside these areas, a coarser mesh was used with an element length having the magnitude of the uncut chip thickness. Another gradation in between was provided to adequately represent the preliminary deformation zone with an element length three times larger than in the primary and secondary shear zone. Also for the tool a graded meshing was implemented with an element size of $e=0.0056 \mathrm{~mm}$ in the area around the cutting edge and $e=0.0326 \mathrm{~mm}$ in the rest of the tool. More specific details along with an illustration of the graded meshing is given in the next section.

With regard to the geometry, the height was chosen to be 15 times the chip thickness and the length was set to $L_{w p}=10 \mathrm{~mm}$. Consequently, a sufficiently long cutting path can be simulated to achieve a clearly steady state with regard to the forces and the chip temperatures. A section of the tool with a height of $H_{t}=2 \mathrm{~mm}$ and a width $B_{t}=1 \mathrm{~mm}$ was modeled. According to the experimental investigation, the rake and clearance angles were set to $\gamma=0^{\circ}$ and $\alpha=10^{\circ}$. The cutting edge was modeled with a radius of $r_{\beta}=10 \mu \mathrm{m}$.

\subsection{Smoothed Particle Hydrodynamics Modeling}

As a Lagrangian mesh-free method particularly suitable for large deformations and free surface problems, Smoothed Particle Hydrodynamics (SPH) is used alongside FEM for chip formation simulations. Previous studies such as $[31,35,38]$ have not only proven the efficiency of SPH in metal cutting simulation but also shown its potential for parallel computing and parameter identification purposes, [39]. A brief overview of the fundamental equations required for solving Equations (1)-(4) with SPH follows.

According to [48,49], the numerical approximation of a function $f$, its gradient $\nabla f$, and its Laplacian $\nabla^{2} f$ using the SPH method can be computed at point (or particle) $i$ from:

$$
\begin{aligned}
\left\langle f_{i}\right\rangle & \approx \sum_{j} f_{j} W_{i j} V_{j} \\
\left\langle\nabla f_{i}\right\rangle & \approx \rho_{i} \sum_{j}\left(\frac{f_{i}}{\rho_{i}^{2}}+\frac{f_{j}}{\rho_{j}^{2}}\right) \nabla W_{i j} m_{j} \\
\left\langle\nabla^{2} f_{i}\right\rangle & \approx \sum_{j} 2\left[\left(\frac{f_{i j}}{\left|r_{i j}\right|}\right) \underline{e}_{i j} \cdot \nabla W_{i j}\right] V_{j}
\end{aligned}
$$


where $W_{i j}=W_{h}\left(\underline{r}_{i}-\underline{r}_{j}, h\right)$ is a kernel function with the smoothing length of $h, V_{j}=m_{j} / \rho_{j}$ is the integration volume of particle $j$ located inside the support domain of particle $i$, and $\underline{e}_{i j}=\underline{r}_{i j} /\left|r_{i j}\right|$ is a unit vector. Also, the notation $(\bullet)_{i j} \equiv(\bullet)_{j}-(\bullet)_{j}$ is used for brevity. The SPH kernel function $W$ in this paper is the Wendland quintic, which was originally derived by [50].

\subsubsection{SPH Discretization of Metal Cutting Equations}

The SPH approximations outlined in Equations (10)-(12) are applied to the balance equations given in Section 3.1, yielding the semi-discretized form of the governing equations as:

$$
\begin{aligned}
& \left\langle\frac{d \rho_{i}}{d t}\right\rangle \approx \rho_{i} \sum_{j} \underline{v}_{i j} \cdot \nabla W_{i j} V_{j} \\
& \left\langle\frac{d \underline{v}_{i}}{d t}\right\rangle \approx \sum_{j}(\frac{\underline{\underline{\sigma}}_{i}}{\rho_{i}^{2}}+\frac{\underline{\underline{\sigma}}_{j}}{\rho_{j}^{2}}+\underbrace{\Pi_{i j} \underline{\underline{I}}+\underline{\underline{\Lambda}}_{i j}}_{\text {stabilizers }}) \cdot \nabla W_{i j} m_{j}+\frac{\underline{b}_{i}}{m_{i}} \\
& \left\langle\frac{d T_{i}}{d t}\right\rangle \approx a_{i} \sum_{j} 2\left[\left(\frac{T_{i j}}{\left|r_{i j}\right|}\right) \underline{\underline{e}}_{i j} \cdot \nabla W_{i j}\right] V_{j}+S_{i}
\end{aligned}
$$

where $a_{i}=k_{i} /\left(\rho_{i} c_{p i}\right)$ is the thermal diffusivity of particle $i, S_{i}=Q_{s i} /\left(\rho_{i} c_{p i}\right)$ its heat source term, and $\Pi$ and $\underline{\underline{\Lambda}}$ are the artificial viscosity and artificial stress tensor generally used for numerical stability of the SPH method (see their original derivation in [51,52]). A more detailed explanation of these the numerical stabilizers and their tuning parameters for $\mathrm{SPH}$ cutting models can be found in $[37,39,53]$. The parameters used in this work are the same as said references.

\subsubsection{Temporal Discretization}

As a common choice in meshfree simulations, the second-order leapfrog method is utilized here for evolving the system of SPH particles. This scheme is an explicit time integration method, and its maximum time step is calculated a priori by enforcing a CourantFriedrichs-Lewy (CFL) criterion through:

$$
\Delta t \leq \underbrace{\mathrm{CFL} \times \min \left(\Delta t_{t}, \Delta t_{m}\right)}_{\Delta t_{\max }}
$$

if the time step constraint of both thermal and mechanical analyses are included as [54,55]:

$$
\begin{aligned}
\Delta t_{t} & =\frac{\rho c_{p} h^{2}}{k} \\
\Delta t_{m} & =\frac{h}{\left(c_{0}+|\underline{v}|_{\max }\right)}
\end{aligned}
$$

in which $c_{0}$ is the sound speed, and the CFL coefficient is less than 0.40 .

\subsubsection{SPH Simulation Setup}

A 2D SPH simulation of the metal cutting process described in Section 2 was carried out using the package mfree_iwf. This open-source code, developed by $[38,56,57]$, is a meshfree Lagrangian solver that can provide efficient solutions to metal cutting and chip formation problems. The CUDA-based implementation in mfree_iwf enables parallel com- 
puting on Graphics Processing Units (GPUs), which is vital for reducing the computational cost of SPH. The GPU-accelerated SPH simulations were performed on a Quadro ${ }^{\circledR}$ GP100 by NVIDIA.

Regarding the workpiece geometry, the height was chosen to be at least three times the chip thickness. The length of the workpiece was set to be $2 \mathrm{~mm}$ for parameter identification purposes and $3 \mathrm{~mm}$ for high-resolution simulations. In all cases, the SPH particles with a smoothing length of $h=1.3 \Delta x$ were initialized on an equidistant grid of size $\Delta x$. To keep a similar resolution in all cases, a reference discretization size was calculated by assuming a minimum of 15 particles in the direction of the uncut chip thickness for the case of $t_{u}=0.15 \mathrm{~mm}$. Also, the same particle size was used to discretize the cutting tool for solving the heat equation.

Properties of the two workpiece materials are listed in Table 8. In order to reduce the simulation time for reaching a steady-state tool temperature, a reduced heat capacity approach of Childs et al. [30] was considered. As mentioned in Section 3.2, the carbide tool is modeled as a rigid body with a cutting radius of $r_{\beta}=10 \mu \mathrm{m}$ in the FEM and SPH simulations of this paper (Tables 2 and 3 ).

Table 8. Material properties of AISI 1045 and Ti6Al4V used for simulations.

\begin{tabular}{lllll}
\hline Property & Symbol & Unit & AISI 1045 & Ti6A14V \\
\hline Density & $\rho$ & $\mathrm{kg} / \mathrm{m}^{3}$ & 7870 & 4430 \\
Young's modulus & $E$ & $\mathrm{GPa}$ & 205 & 110 \\
Poisson ratio & $v$ & - & 0.29 & 0.342 \\
Heat conductivity & $k$ & $\mathrm{~W} /(\mathrm{m} \mathrm{K})$ & 50.7 & 7.44 \\
Specific heat capacity & $c_{p}$ & $\mathrm{~J} /(\mathrm{kg} \mathrm{K})$ & 486 & 553 \\
Melting temperature & $T_{m}$ & $\mathrm{~K}$ & 1773 & 1877 \\
\hline Reference temperature & $T_{r}$ & $\mathrm{~K}$ & & 293 \\
Coeff. of plastic work into heat & $\chi$ & - & & 0.9 \\
Coeff. of frictional work into heat & $\eta$ & - & & 1 \\
\hline
\end{tabular}

\section{Results and Discussion}

This section investigates the SPH and FEM numerical errors of predicting the thermal and mechanical loads in orthogonal metal cutting problems. A total of 18 test cases according to the information provided in Tables 2 and 3 were studied.

\subsection{Prediction of Mechanical Loads}

As a first validation of the numerical results, process forces predicted by the FEM and SPH simulations need to be compared against the experimental data. For each material, nine test cases are examined with the force measurements given in Tables 2 and 3. Three different friction coefficients are alternatively used in each SPH and FEM model: (1) constant $\mu$; (2) temperature-dependent $\mu(T)$; and (3) velocity-dependent $\mu(v)$. This variation of 2 materials, 9 cutting geometries, 2 numerical methods, and 3 friction coefficients amounts to a total of 108 simulations.

Figure 5 plots the relative error of force predictions for AISI 1045 and Ti6Al4V. Each error bar in this figure indicates an average of 9 data points ( 3 uncut chip thicknesses at 3 cutting speeds). The numerical values of the errors used for plotting these graphs are provided in Tables A1 and A2 in Appendix A. The constant friction coefficients in Figure 5 are taken as $\mu=0.76$ for AISI 1045 and $\mu=0.56$ for Ti6Al4V, which correspond to the two representative experiments with medium values for $v_{c}$ and $t_{u}$. This makes the comparison more meaningful as the parameters of $\mu(T)$ and $\mu(v)$ were also determined by force optimization of the same representative experiments. 

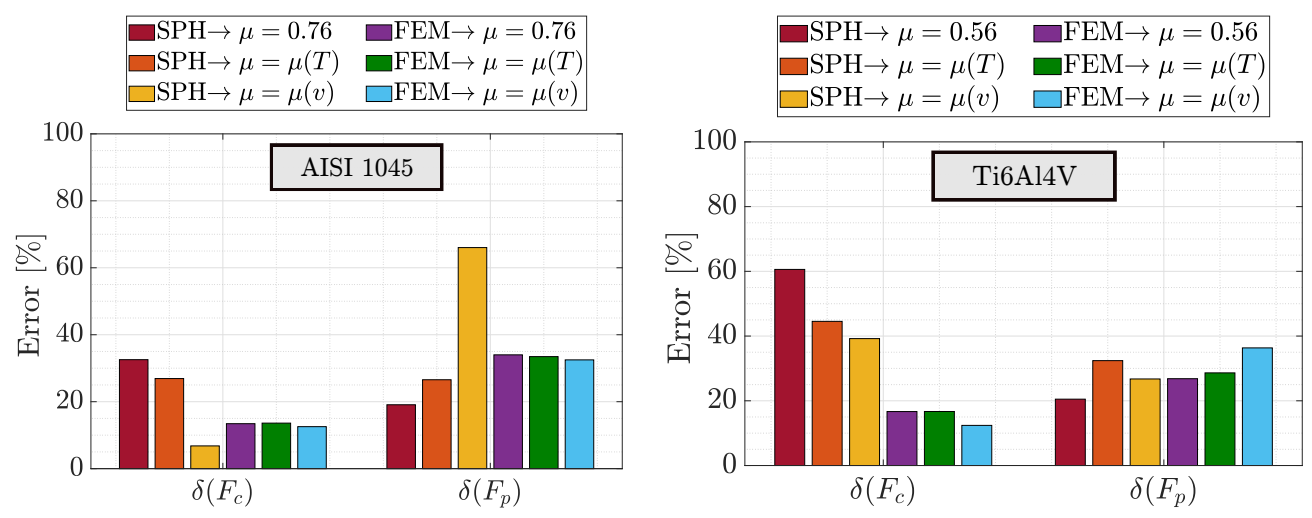

Figure 5. Overall percent error of force prediction in SPH and FEM using different friction coefficients. FEM results of AISI 1045 are computed with the modified JC model, given in Equation (7). Each error bar represents an average of 9 data points resulting from the variation of 3 cutting velocities and 3 uncut chip thicknesses for each material, as listed in Tables 2 and 3, where $\gamma=0^{\circ}, \alpha=10^{\circ}$, and $r_{\beta}=10 \mu \mathrm{m}$ in all cases.

The predicted forces in the FE chip formation simulation are subject to a significant influence of the flow stress model used. When using the standard Johnson-Cook model, both $F_{c}$ and $F_{p}$ are largely overestimated. As a consequence the results are not presented. By using the modified model according to Equation (7), both force components can be remarkably reduced over the entire test plan. This is due to the fact that the modeling of the strain hardening can be represented more realistically by keeping the corresponding term constant in the model from a strain of $\varepsilon=2$. For the passive force prediction, this leads to a slight deterioration of the prediction accuracy, but the influence is smaller than for the cutting force, for which a considerable improvement of the prediction accuracy can be achieved. This modified approach was not implemented into the SPH code, however.

Except for two SPH cases of using $\mu(v)$ for AISI 1045 and $\mu=0.56$ for Ti6Al4V, all numerical approximation errors are approximately within the $5-40 \%$ range. The erroneous prediction of $F_{p}$ can be ascribed to the inaccuracy of friction modeling at the rake face, especially at severe contact conditions and very high temperatures. Furthermore, the reason for the large error can also be a large deviation between the calculated and the measured contact length between chip and tool. This will be analyzed in future studies. The magnitude of cutting forces, on the other hand, is heavily affected by the choice of JC material parameters (see in $[30,58]$ for more explanation). A solution to resolve this issue would be identifying the JC parameters directly from the cutting experiments instead of the standard material tests like SHPB. In such a way, extreme conditions of the strain, strain rates, and temperatures (encountered in high-speed metal cutting) are reflected in the identified material parameters.

Figure 6 demonstrates the sensitivity of process forces to the cutting speed. This parameter study pertains to the experiments with an uncut chip thickness of $t_{u}=0.1 \mu \mathrm{m}$. As seen in the plots, increasing the cutting speed has no significant impact on the predicted forces in most cases. The experimental observation confirms this, clearly seen by tracking the green graphs in Figure 6. Similar to the overall relative error shown in Figure 5, the least accurate prediction is again generated by using $\mu(v)$ for AISI 1045 in SPH. Quite interestingly, the best prediction of passive forces for both materials was found using SPH with a constant $\mu$. These apparent coefficients of friction, as described in Section 3.1.2 and plotted in Figure 2, were directly obtained from the cutting experiments, thus producing passive forces very close to the experiments. In the case of Ti6Al4V, the trend of slightly decreasing forces with increasing cutting speed cannot be mapped by the FEM model. In this case, occurring changes (independent from the friction model used) in the chip curling lead to a slight increase of the forces. Another test for a cutting speed of $v_{\mathcal{C}}=180 \mathrm{~m} / \mathrm{min}$, which has a lower cutting force than the simulations discussed here, shows that the FEM model in general addresses the mechanism of thermal modeling. If a higher level of 
accuracy is needed, the FEM modeling approach needs modification for the cutting speed regime investigated within this paper.

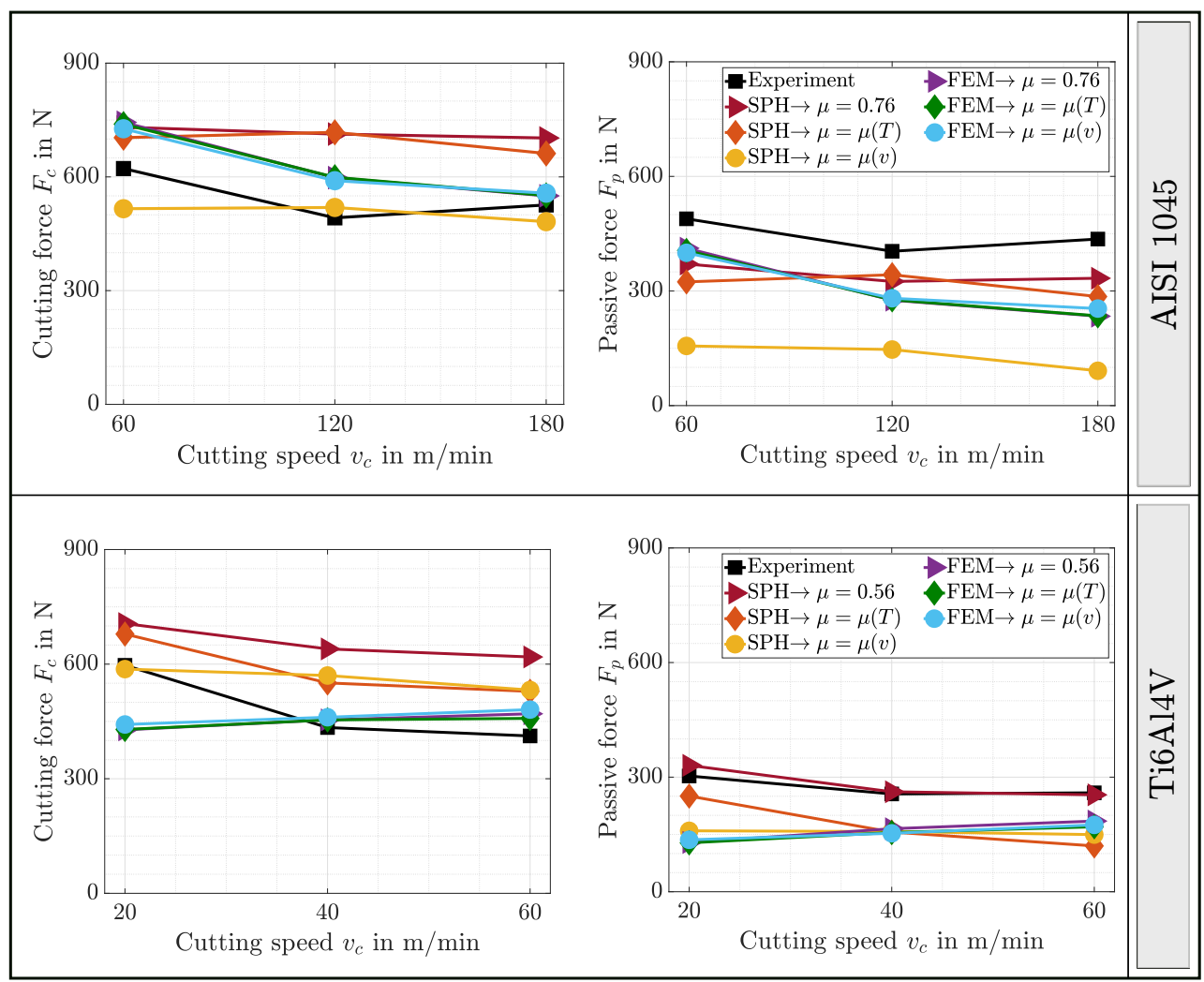

Figure 6. Comparison of measured and predicted forces for $t_{u}=0.10 \mathrm{~mm}$ at different cutting speeds.

\subsection{Prediction of Thermal Loads}

The experimentally measured temperatures are interpolated as a function of $v_{c}$ and $t_{u}$ to generate insight into the effects of cutting parameters on the thermal loads in metal cutting. According to the raw data in Tables 2 and 3, the difference between the minimum and maximum free chip surface temperatures $\left(T_{F C S}\right)$ was insignificant. This value for AISI 1045 and Ti6Al4V is below $6 \%$ and $9 \%$, respectively. Presumably, the reason for this is that the temperatures at the free chip surface result mainly from near-surface deformations in the primary shear zone. The material remains in the chip formation zone for too short a time for heat to be conducted to the top side of the chip from the areas with greater heat generation, which increases due to the cutting values, in the region of the stagnation and separation point and the secondary shear zone.

The impact of cutting parameters on the rake face temperature $\left(T_{R F}\right)$, however, was notably more significant. In both materials, the maximum rake face temperature was found at the highest cutting speed and the largest uncut chip thickness. As a result from an increasing cutting speed, the cutting power is enlarged which means that more energy per time is brought into the chip formation zone, especially close to the cutting edge and the rake face. This results in higher temperatures on the tool. An increase in the uncut chip thickness has the same effect based on two different causes: a higher uncut chip thickness leads to a longer tool-chip-contact length which results in more frictional heat on one side and more energy resulting from material deformation in the enlarged primary shear zone. Figure 7 summarizes all these observations by plotting the interpolated temperature surfaces as a function of $v_{\mathcal{c}}$ and $t_{u}$. The black stems in these plots indicate the 36 experimental data points. 
639

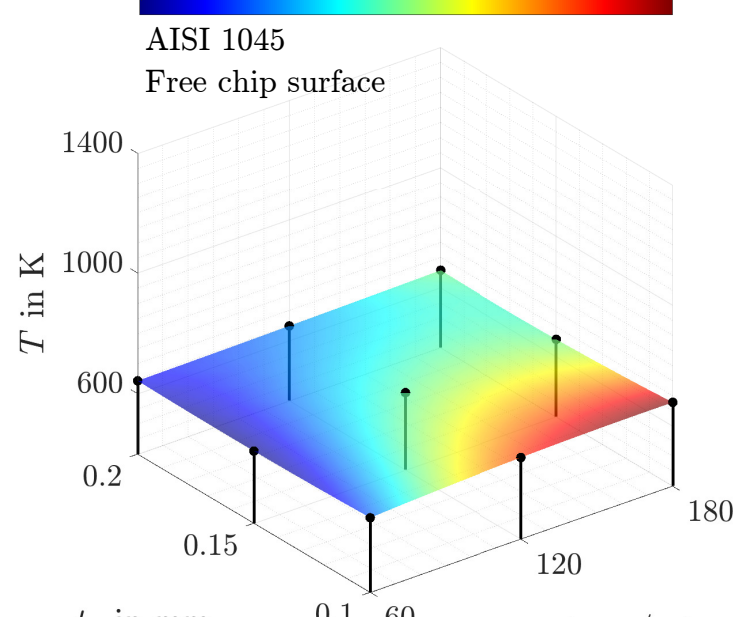

$t_{u}$ in $\mathrm{mm}$

$0.1 \quad 60$

$v_{c}$ in $\mathrm{m} / \mathrm{min}$

665

728

Ti6Al4V

Free chip surface

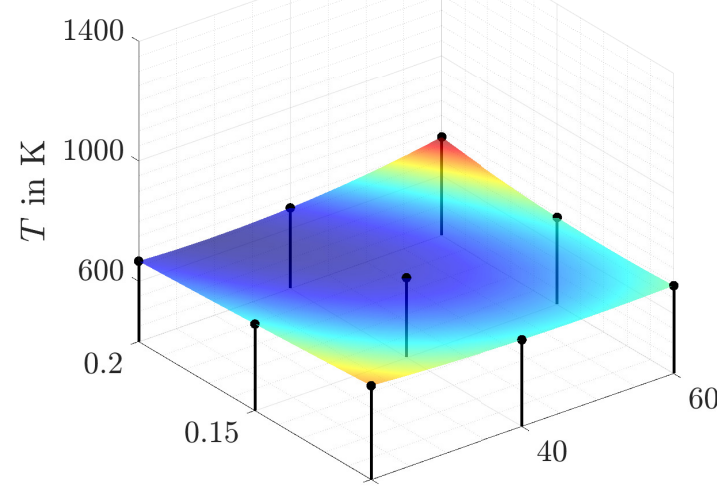

$t_{u}$ in $\mathrm{mm}$

$0.120 \quad v_{c}$ in $\mathrm{m} / \mathrm{min}$

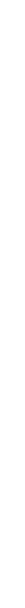

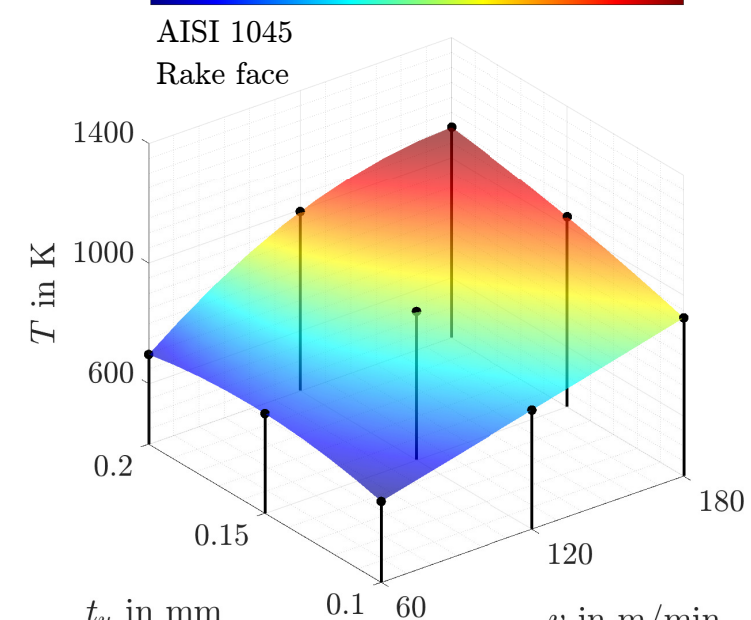

$t_{u}$ in $\mathrm{mm}$

$0.1 \quad 60$

$v_{c}$ in $\mathrm{m} / \mathrm{min}$
$690 \quad 998$

\section{Ti6Al4V}

Rake face

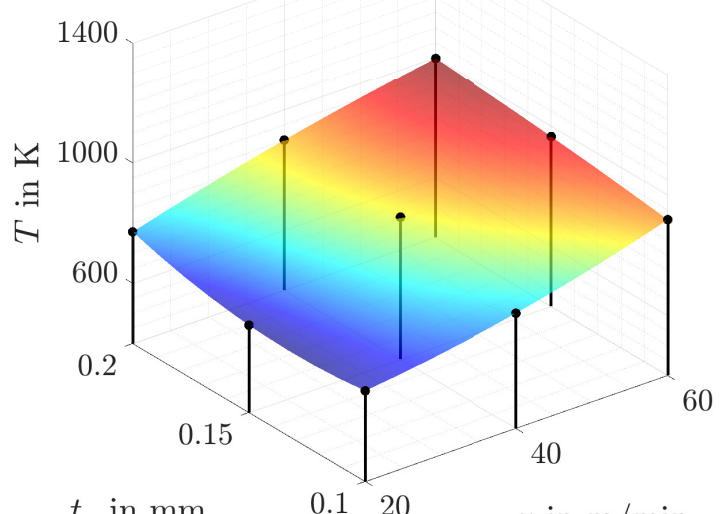

Figure 7. Experimentally measured temperatures plotted as a function of $v_{c}$ and $t_{u}$.

For thermal modeling in the SPH code, the tool and workpiece were treated as a single body but using particles with different thermal conductivity coefficients. The thermal contact are thus naturally handled via the SPH particle-particle interaction. To find the boundary particles for imposing the thermal boundary condition, the enhanced scheme of [40] was employed. This newly proposed thermal modeling approach incorporates a free-surface detection algorithm to identify the interface particles. As a result, the SPH model can resolve the Neumann boundary condition with a negligible computational overhead. Figure 8 shows the temperature distribution at a $2 \mathrm{~mm}$ cutting distance, where the high-resolution results are obtained from the CUDA-accelerated simulations. The diameter of the SPH particles in the initial configuration of these two models was $3 \mu \mathrm{m}$. For Ti6Al4V, the temperature in the chip formation zone is too high because the time for thermal conduction is too short and the heat is not diffused sufficiently. This situation leads to a nearly adiabatic process - a common assumption in most Ti6Al4V cutting simulations. For AISI 1045, on the other hand, the thermal diffusivity, $\alpha=k /\left(\rho c_{p}\right)$, is five times higher than Ti6Al4V (see in Table 8) and thermal conduction is considerably more pronounced. Comparing the temperature distribution between the AISI 1045 and Ti6Al4V chips clarifies this behavior, vividly seen in Figure 8. 
Despite being able to represent the chip curling process rather nicely, the present model could not capture chip serration in Ti6Al4V (see in Figure 8). As elaborated upon by Childs et al. [30], some form of strain-softening (or failure law) is necessary to account for sawtooth shaped and serrated chip formation in cutting titanium alloys. A constitutive model with this capability exists, e.g., the so-called TANH flow stress rule presented in [59], and has already been used in both SPH [41] and FEM [59] metal cutting simulations. However, we did not follow this approach here as the number of unknown material parameters in such a model is generally high.

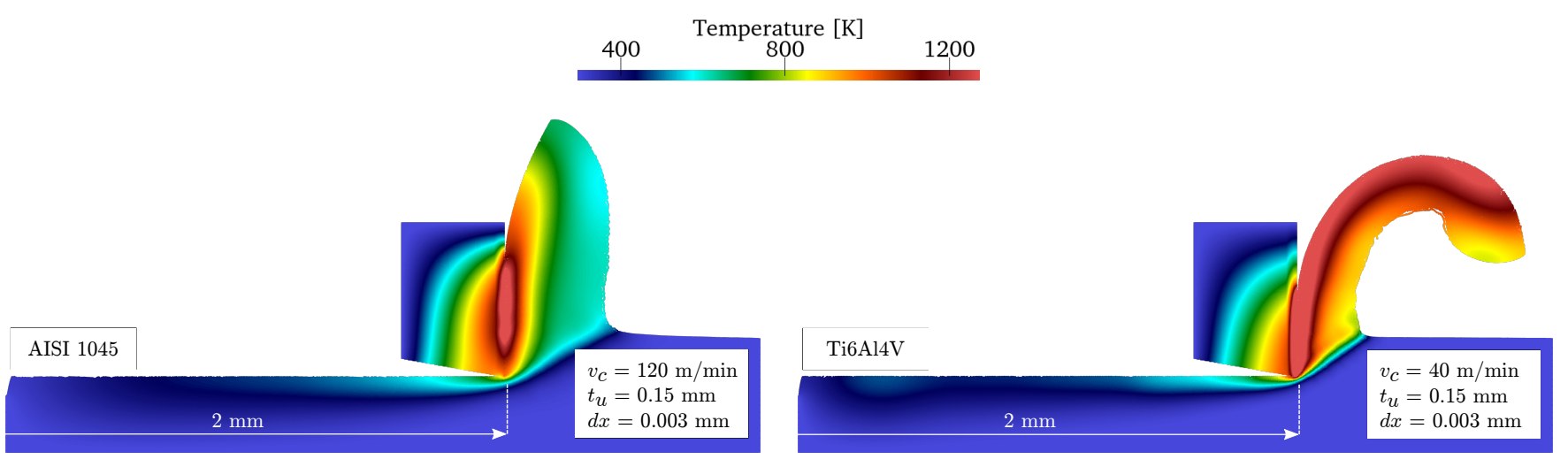

Figure 8. Temperature distribution in high-resolution SPH using $\mu(T)$. For better visibility, the color-bar limits are set to 293 and $1273 \mathrm{~K}$.

Within the finite element simulations in DEFORM, a different method for predicting the tool temperatures was chosen. In the thermo-mechanically coupled model, only a short cutting duration can be simulated due to the high computational effort resulting from the remeshing procedure and large deformation issues. For this reason, a second purely thermal model was added to the thermomechanical simulation, in which no further deformations are considered and the cutting speed is set to $v_{c}=0 \mathrm{~m} / \mathrm{min}$. The temperature at the upper border nodes is set to room temperature, while at all other border nodes a heat exchange with the environment is defined. The temperature distribution in the workpiece and chip determined in the thermomechanical simulation was kept constant and the frictional heat determined in the stationary area of the thermomechanical simulation was imposed as a boundary condition at the contact nodes of the tool and workpiece, as well as the tool and chip. The temporal resolution is coarsely selected with a time step of $t=0.1 \mathrm{~s}$, so that a contact duration of several seconds can be represented with little computational effort. The tool temperatures predicted with this model, result from the heat conduction of chip and workpiece into the tool and from the temperature increase caused by the frictional heat for a significantly larger simulated contact duration compared to the thermomechanical model. The transferred values and the boundary conditions of the thermal simulation, as well as the heat flows, are illustrated in Figure 9.

Figure 10 shows the differences in the temperature distribution for the last step of the thermomechanical simulation and the stationary temperature distribution of the purely thermal simulation as an example for a cutting speed of $v_{\mathcal{C}}=180 \mathrm{~m} / \mathrm{min}$ and an uncut chip thickness of $t_{u}=0.2 \mathrm{~mm}$. It can be seen that the additional thermal simulation predicts significantly higher values both in terms of the maximum temperature and in terms of the tool temperatures. In the experimental investigations, the temperature in the area of the measuring spot was recorded and output as an averaged measured value. In order to transfer this procedure for temperature measurement to the simulation results, regions of interest must be defined in which an average value of the temperature is calculated. The real measurement spot in the experiment is a circular area, having a diameter depending on the distance between the pyrometer fiber and the measurement object. The distance between the pyrometer fiber and the rake face results in a measuring spot diameter of $d=1.2 \mathrm{~mm}$ for determining the temperature prevailing there. 

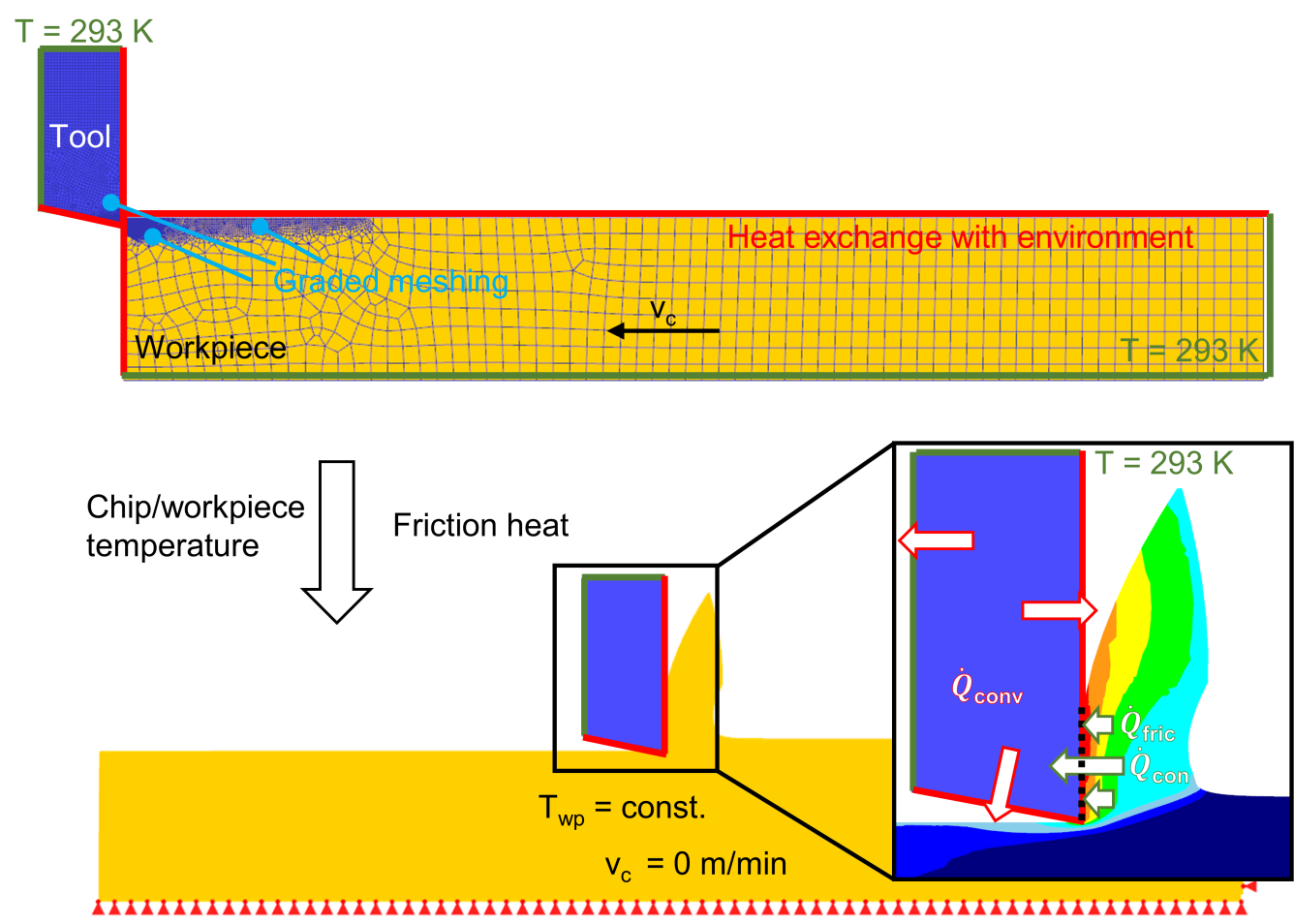

Figure 9. Schematic illustration of the boundary conditions for the thermal simulation in FEM for AISI 1045.

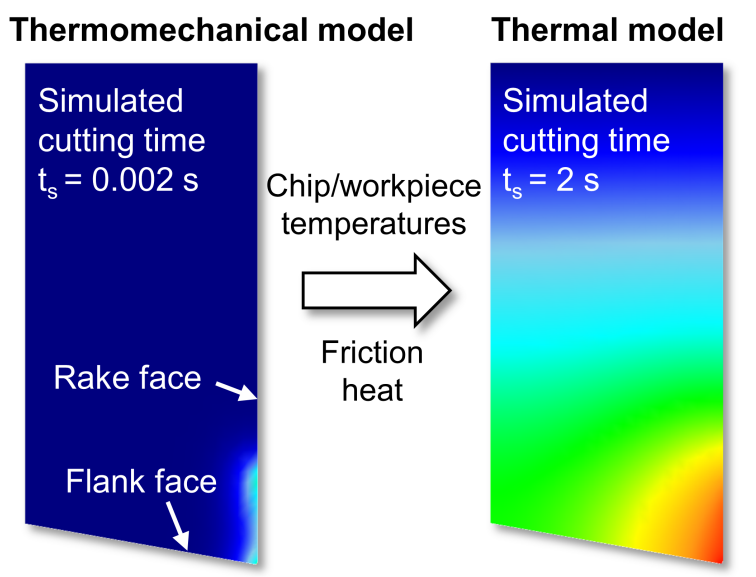

\section{Measurment of temperatures}

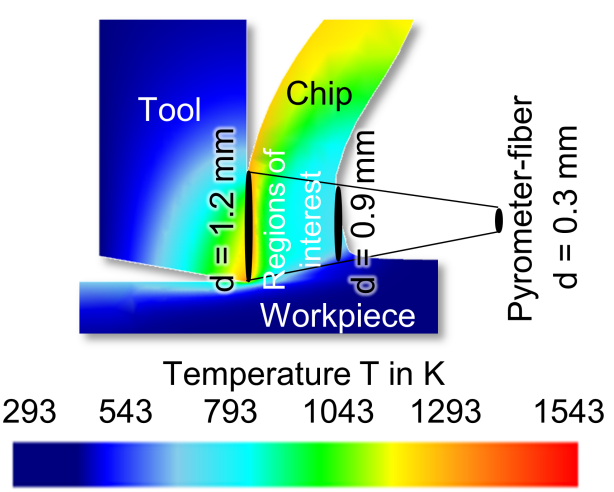

Figure 10. Schematic illustration of the thermomechanical and the thermal FE model with resulting temperature distribution for AISI 1045.

In the case of the chip temperature, depending on the chip thickness, different distances between the upper side of the chip and the pyrometer fiber and, as a result, different measuring spot diameters are obtained. Since the temperatures on the upper side of the chip show relatively low gradients in the simulations, an average value was calculated for all chip thicknesses, which is $d=0.9 \mathrm{~mm}$. This principle is illustrated in Figure 10. In this case, node temperatures were read out in the respective region of interest at equal intervals along the measuring length and an average value was formed from the measured temperatures.

A bar-chart comparison of the predicted temperatures versus the experimental data is shown in Figure 11. The SPH results using different friction coefficients were more or less similar for both AISI 1045 and Ti6Al4V, showing that the impact of $\mu$ on the thermal load of metal cutting is less significant than on the mechanical load (Figure 5). Concerning the free chip surface temperature, the measured values from both FEM and $\mathrm{SPH}$ simulations were reasonably close to those of the cutting experiments (error below $20 \%$ ). Corresponding to the mechanical loads, the standard version of the Johnson-Cook 
model leads to a slight overestimation of the temperatures, while the modified JohnsonCook model leads to a slight underestimation. However, the influence is much smaller than in the case of force prediction. For both models, the prediction qualities are good. At the rake face of Ti6Al4V, nonetheless, the numerically predicted temperatures were far from the experimental measurements (error approximately 60\%). In this case, both SPH and FEM simulations failed to approximate the rake face temperature by producing results that were largely overestimated. Interestingly enough, the error of thermal modeling in the FEM and SPH chip formation simulations was observed in both methods quite similarly, despite using two completely independent software tools, i.e., DEFORM2D ${ }^{\circledR}$ and $\mathrm{mfree}_{-} \mathrm{iwf}$.

This relatively large error of $T_{R F}$ in Ti6Al4V can be the result of a few factors, which are more likely associated with the physical model of the process rather than its computational model. First, a direct parameter identification approach could be necessary to account for the extreme conditions in metal cutting. In other words, the JC parameters obtained from standard SHPB material tests need to be determined directly from cutting experiments, analogous to the parameter identification procedure of $\mu(T)$ in this work. The second source of error lies in the considerable amount of heat introduced by friction at the rake face, where frictional behavior was kept simple by assuming Coulomb's friction throughout the tool-chip interface. Utilizing a more sophisticated friction model, the sticking-sliding approach of [60] for instance, would be worthwhile to assess the interplay between the thermal and frictional loads. Finally, the tool-chip-contact length is very small in the finite element simulations. Due to that, the area for frictional heat and heat conduction from the chip to the tool is underestimated. However, this error does not stem from the friction modeling approach but mainly from the mechanical weakening overestimation, which originates from the chip segmentation. This effect leads to a high curvature of the generated chip, resulting in a short contact length between the tool and chip.
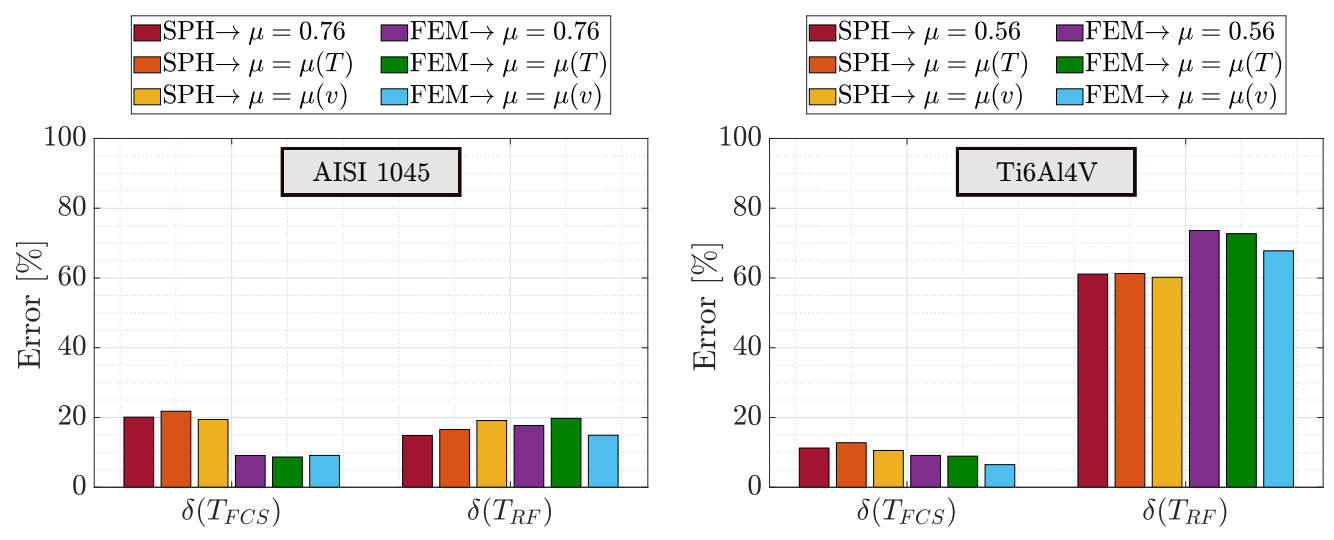

Figure 11. Relative error of numerical simulations in predicting the free chip surface and rake face temperatures. Each error bar represents an average of 9 data points resulting from the variation of 3 cutting velocities and 3 uncut chip thicknesses for each material, as listed in Tables 2 and 3 , where $\gamma=0^{\circ}, \alpha=10^{\circ}$, and $r_{\beta}=10 \mu \mathrm{m}$ in all cases.

\section{Conclusions}

In this work, the thermo-mechanical aspects of orthogonal metal cutting were simulated using both a mesh-free (SPH) and mesh-dependent (FEM) method. Force and temperature measurements from a series of cutting experiments were used to validate the SPH-FEM numerical simulation results, representing an advance in the current state of the art in computational models of machining processes. An outline of the novelties offered by this work is as follows:

- Development of a novel methodology to measure the rake face temperature in orthogonal metal cutting without manipulating the chip flow to achieve data for validating the thermal prediction of chip formation simulations on a new level of accuracy. 
- Proposing new values for temperature-dependent and velocity-dependent friction coefficients of AISI 1045 and Ti6Al4V under the cutting conditions using an inverse parameter identification approach.

- Identification of the flow stress and friction parameters via in-house experimental measurements, enabling a more consistent set of input parameters for SPH and FEM simulations.

The main findings of this study can be summarized as:

- Average errors of force prediction for SPH and FEM were in the range of $33 \%$ and $23 \%$, respectively. The highest errors were around $60 \%$ in $\mathrm{SPH}$, computed for the passive force of AISI 1045 using $\mu(v)$ and the cutting force of Ti6Al4V with $\mu=0.56$. In other cases, the SPH and FEM methods calculated the process forces with satisfactory precision.

- The cutting forces predicted by FEM were more accurate than SPH in most cases.

- The choice of friction coefficient had a relatively higher impact on SPH forces than FEM.

- Except for the rake face temperature of Ti6Al4V, both SPH and FEM provided accurate predictions of thermal loads with $5-20 \%$ error.

A simple correction for reducing the difference between the present SPH and FEM results is implementing the modified JC equation into the SPH code. Concerning the predicted temperatures at the rake face of Ti6Al4V, reasons for the large deviation of numerical results can be sought in the modeling of friction and plasticity, as well as the conversion of frictional and plastic deformation work into heat.

Future developments will focus on incorporating more realistic friction and material modeling approaches in order to provide a better description of the cutting process. Parameter identification of the Johnson-Cook flow stress, and other constitutive models as a whole, is also within the reach of highly efficient simulations using the present GPU accelerated SPH code. The parameters of the constitutive equations must be carried out together with the parameters of the friction model. The SPH-FEM coupling to mutually leverage the strength of each method will be another objective of future efforts.

Author Contributions: Conceptualization, M.A. and J.S.; methodology, M.A., J.S. and S.B.; software, M.A., J.S., H.K. and M.R.; validation, M.A., J.S. and S.B.; formal analysis, M.A. and J.S.; investigation, M.A., J.S. and S.B.; data curation, M.A., J.S. and S.B.; writing-original draft preparation, M.A. and J.S.; writing-review and editing, M.A. and J.S.; visualization, M.A. and J.S.; supervision, I.I., A.Z., D.B. and K.W.; project administration, D.B. and K.W.; funding acquisition, D.B. and K.W. All authors have read and agreed to the published version of the manuscript.

Funding: This research was funded by Swiss National Science Foundation grant number 200021149436 and the German Research Foundation (DFG) grant number 439919057.

Institutional Review Board Statement: Not applicable.

Informed Consent Statement: Not applicable.

Data Availability Statement: Not applicable.

Conflicts of Interest: The authors declare no conflict of interest. The funders had no role in the design of the study; in the collection, analyses, or interpretation of data; in the writing of the manuscript; or in the decision to publish the results.

\section{Nomenclature}

$\alpha \quad$ Clearance angle (degree)

$\gamma \quad$ Rake angle (degree)

$\mu \quad$ Coefficient of friction (-)

$\rho \quad$ Density $\left(\mathrm{kg} / \mathrm{m}^{3}\right)$

$F_{c} \quad$ Cutting force $(\mathrm{N})$ 


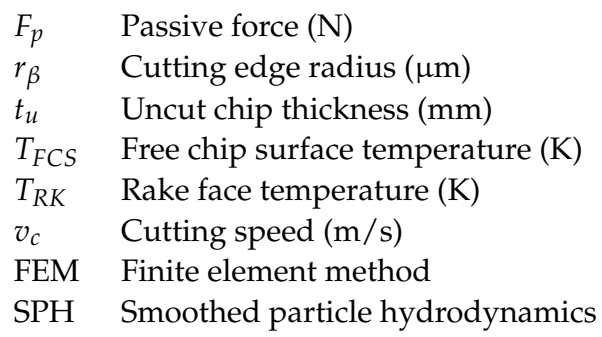

\section{Appendix A}

The numerical values of the errors used to plot the graphs in Figure 5 are provided in Tables A1 and A2.

Table A1. Force prediction errors of SPH and FEM for AISI 1045 using different friction coefficients.

\begin{tabular}{llcc}
\hline Model & Average Error of $\boldsymbol{F}_{\boldsymbol{c}}(\mathbf{\%})$ & Average Error of $\boldsymbol{F}_{\boldsymbol{p}} \mathbf{( \% )}$ \\
\hline SPH with & $\mu=0.76$ & 32.5 & 19 \\
SPH with & $\mu(T)$ & 26.9 & 26.5 \\
SPH with & $\mu(v)$ & 6.7 & 66 \\
FEM with $\mu=0.76$ & 13.4 & 33.9 \\
FEM with & $\mu(T)$ & 13.6 & 33.4 \\
FEM with & $\mu(v)$ & 12.5 & 32.4 \\
\hline
\end{tabular}

Table A2. Force prediction errors of SPH and FEM for Ti6Al4V using different friction coefficients.

\begin{tabular}{llcc}
\hline Model & Average Error of $\boldsymbol{F}_{\boldsymbol{c}}(\mathbf{\%})$ & Average Error of $\boldsymbol{F}_{\boldsymbol{p}} \mathbf{( \% )}$ \\
\hline SPH with & $\mu=0.56$ & 60.5 & 20.5 \\
SPH with & $\mu(T)$ & 44.5 & 32.4 \\
SPH with & $\mu(v)$ & 39.2 & 26.7 \\
FEM with $\mu=0.56$ & 16.6 & 26.8 \\
FEM with $\mu(T)$ & 16.7 & 28.6 \\
FEM with $\mu(v)$ & 12.4 & 36.3 \\
\hline
\end{tabular}

\section{References}

1. Berger, S.; Brock, G.; Biermann, D. Simulative design of constraints for targeted restriction of chip thickness deviations when machining titanium alloy Ti6Al4V materials. Procedia CIRP 2021, 102, 85-90. [CrossRef]

2. M'Saoubi, R.; Axinte, D.; Leung Soo, S.; Nobel, C.; Attia, H.; Kappmeyer, G.; Engin, S.; Sim, W.M. High performance cutting of advanced aerospace alloys and composite materials. CIRP Ann.-Manuf. Technol. 2015, 64, 557-580. [CrossRef]

3. Umbrello, D. Finite element simulation of conventional and high speed machining of Ti6Al4V alloy. J. Mater. Process. Technol. 2008, 196, 79-87. [CrossRef]

4. Pimenov, D.Y.; Guzeev, V. Mathematical model of plowing forces to account for flank wear using FME modeling for orthogonal cutting scheme. Int. J. Adv. Manuf. Technol. 2017, 89, 3149-3159. [CrossRef]

5. Attanasio, A.; Ceretti, E.; Rizzuti, S.; Umbrello, D.; Micari, F. 3D finite element analysis of tool wear in machining. CIRP Ann. 2008, 57, 61-64. [CrossRef]

6. Melkote, S.N.; Grzesik, W.; Outeiro, J.; Rech, J.; Schulze, V.; Attia, H.; Arrazola, P.J.; M'Saoubi, R.; Saldana, C. Advances in material and friction data for modelling of metal machining. CIRP Ann.-Manuf. Technol. 2017, 66, 731-754. [CrossRef]

7. Vakis, A.; Yastrebov, V.A.; Scheibert, J.; Nicola, L.; Dini, D.; Minfray, C.; Almqvist, A.; Paggi, M.; Lee, S.; Limbert, G.; et al. Modeling and simulation in tribology across scales. An overview. Tribol. Int. 2018, 125, 169-199. [CrossRef]

8. Arrazola, P.; Özel, T.; Umbrello, D.; Davies, M.; Jawahir, I. Recent advances in modelling of metal machining processes. CIRP Ann.-Manuf. Technol. 2013, 62, 695-718. [CrossRef]

9. Zemzemi, F.; Bensalem, W.; Rech, J.; Dogui, A.; Kaps, P. New tribometer designed for the characterisation of the friction properties at the tool/chip/workpiece interfaces in machining. Tribotest 2008, 14, 11-12. [CrossRef]

10. Rech, J.; Arrazola, P.; Claudin, C.; Courbon, C.; Pusavec, F.; Kopac, J. Characterisation of friction and heat partition coefficients at the tool-work material interface in cutting. CIRP Ann. 2013, 62, 79-82. [CrossRef]

11. Meier, L.; Schaal, N.; Wegener, K. In-process Measurement of the Coefficient of Friction on Titanium. Procedia Cirp 2017, $58,163-168$. [CrossRef] 
12. Puls, H.; Klocke, F.; Lung, D. A new experimental methodology to analyse the friction behaviour at the tool-chip interface in metal cutting. Prod. Eng. Res. Dev. 2012, 6, 349-354. [CrossRef]

13. Puls, H.; Klocke, F.; Lung, D. Experimental investigation on friction under metal cutting conditions. Wear 2014, 310, 63-71. [CrossRef]

14. Peng, B.; Bergs, T.; Schraknepper, D.; Smigielski, T.; Klocke, F. Development and validation of a new friction model for cutting processes. Int. J. Adv. Manuf. Technol. 2020, 107, 4357-4369. [CrossRef]

15. Zanger, F.; Bollig, P.; Schulze, V. Simulative investigations on different friction coefficient models. Procedia CIRP 2017, 58, 140-145. [CrossRef]

16. Tapetado, A.; Diaz-Alvarez, J.; Miguelez, M.H.; Vasquez, C. Two-Color Pyrometer for Process Temperature Measurement During Machining. J. Light. Technol. 2016, $34,1380-1386$. [CrossRef]

17. Davies, M.A.; Ueda, T.; M'Saoubi, R.; Mullany, B.; Cooke, A.L. On The Measurement of Temperature in Material Removal Processes. CIRP Ann.-Manuf. Technol. 2007, 56 , 581-604. [CrossRef]

18. Al Huda, M.; Yamada, K.; Hosokawa, A.; Takashi, U. Investigation of Temperature at Tool-Chip Interface in Turning Using Two-Color Pyrometer. J. Manuf. Sci. Eng. 2002, 124, 200-207. [CrossRef]

19. Müller, B.; Renz, U.; Hoppe, S.; Klocke, F. Radiation Thermometry at a High-Speed Turning Process. J. Manuf. Sci. Eng. 2004, 126, 488-495. [CrossRef]

20. Dörr, J.; Mertens, T.; Engering, G.; Lahres, M. 'In-situ' temperature measurement to determine the machining potential of different tool coatings. Surf. Coat. Technol. 2003, 174-175, 389-392. [CrossRef]

21. Oezkaya, E.; Bücker, M.; Strodick, S.; Biermann, D. A thermomechanical analysis leading to a novel flank face design providing longer tool lives for tools used in the drilling of Inconel 718. Int. J. Adv. Manuf. Technol. 2019, 102, 2977-2992. [CrossRef]

22. Nishimoto, H.; Tanaka, R.; Hosokawa, A.; Takashi, U.; Furumoto, T. Development of Tool Edge Temperature Measurement Method in Wet Cutting. J. Adv. Mech. Des. Syst. Manuf. 2012, 6, 916-922. [CrossRef]

23. Kus, A.; Isik, Y.; Cemal, C.M.; Coskun, S.; Özdemir, K. Thermocouple and infrared sensor-based measurement of temperature distribution in metal cutting. Sensors 2015, 15, 1274-1291. [CrossRef] [PubMed]

24. Le Coz, G.; Marinescu, M.; Devillez, A.; Dudzinski, D.; Velnom, L. Measuring temperature of rotating cutting tools. Application to MQL drilling and dry milling of aerospace alloys. Appl. Therm. Eng. 2012, $36,434-441$. [CrossRef]

25. Basti, A.; Obikawa, T.; Shinozuka, J. Tools with built-in thin film thermocouple sensors for monitoring cutting temperature. Int. J. Mach. Tools Manuf. 2006, 47, 793-798. [CrossRef]

26. Li, T.; Shi, T.; Tang, Z.; Liao, G.; Han, J.; Duan, J. Temperature monitoring of the tool-chip interface for PCBN tools using built-in thin-film thermocouples in turning of titanium alloy. J. Mater. Process. Technol. 2020, 275,116376 . [CrossRef]

27. Augspurger, T.; Bergs, T.; Döbbeler, B.; Lima, A. Methodology for the Measurement of the Heat Partitioning by Thermal Imaging in the Orthogonal Cutting Process. J. Heat Transf. 2019, 147, 85-91. [CrossRef]

28. Arrazola, P.J.; Aristimuno, P.; Soler, D.; Childs, T. Metal cutting experiments and modelling for improved determination of chip/tool contact temperature by infrared thermography. CIRP Ann.-Manuf. Technol. 2015, 64, 57-60. [CrossRef]

29. Saelzer, J.; Berger, S.; Iovkov, I.; Zabel, A.; Biermann, D. In-situ measurement of rake face temperatures in orthogonal cutting. CIRP Ann. 2020, 69, 61-64. [CrossRef]

30. Childs, T.H.; Arrazola, P.J.; Aristimuno, P.; Garay, A.; Sacristan, I. Ti6Al4V metal cutting chip formation experiments and modelling over a wide range of cutting speeds. J. Mater. Process. Technol. 2018, 255, 898-913. [CrossRef]

31. Limido, J.; Espinosa, C.; Salaün, M.; Lacome, J.L. SPH method applied to high speed cutting modelling. Int. J. Mech. Sci. 2007, 49, 898-908. [CrossRef]

32. Ruttimann, N.; Buhl, S.; Wegener, K. Simulation of single grain cutting using SPH method. J. Mach. Eng. 2010, 10, 17-29.

33. Madaj, M.; Piška, M. On the SPH orthogonal cutting simulation of A2024-T351 alloy. Procedia CIRP 2013, 8, 152-157. [CrossRef]

34. Spreng, F.; Schnabel, D.; Mueller, A.; Eberhard, P. A local adaptive discretization algorithm for Smoothed Particle Hydrodynamics. Comput. Part. Mech. 2014, 1, 131-145. [CrossRef]

35. Afrasiabi, M.; Roethlin, M.; Klippel, H.; Wegener, K. Meshfree simulation of metal cutting: An updated Lagrangian approach with dynamic refinement. Int. J. Mech. Sci. 2019, 160C, 451-466. [CrossRef]

36. Niu, W.; Mo, R.; Liu, G.; Sun, H.; Dong, X.; Wang, G. Modeling of orthogonal cutting process of A2024-T351 with an improved SPH method. Int. J. Adv. Manuf. Technol. 2018, 95, 905-919. [CrossRef]

37. Röthlin, M.; Klippel, H.; Afrasiabi, M.; Wegener, K. Metal cutting simulations using smoothed particle hydrodynamics on the GPU. Int. J. Adv. Manuf. Technol. 2019, 102, 3445-3457. [CrossRef]

38. Roethlin, M.; Klippel, H.; Afrasiabi, M.; Wegener, K. Meshless single grain cutting simulations on the GPU. Int. J. Mechatron. Manuf. Syst. 2019, 12, 272-297. [CrossRef]

39. Afrasiabi, M.; Meier, L.; Röthlin, M.; Klippel, H.; Wegener, K. GPU-accelerated meshfree simulations for parameter identification of a friction model in metal machining. Int. J. Mech. Sci. 2020, 176, 105571. [CrossRef]

40. Afrasiabi, M.; Klippel, H.; Roethlin, M.; Wegener, K. Smoothed Particle Hydrodynamics Simulation of Orthogonal Cutting with Enhanced Thermal Modeling. Appl. Sci. 2021, 11, 1020. [CrossRef]

41. Afrasiabi, M.; Klippel, H.; Röthlin, M.; Wegener, K. An improved thermal model for SPH metal cutting simulations on GPU. Appl. Math. Model. 2021, 100, 728-750. [CrossRef] 
42. Issa, M.; Saanouni, K.; Labergère, C.; Rassineux, A. Prediction of serrated chip formation in orthogonal metal cutting by advanced adaptive 2D numerical methodology. Int. J. Mach. Mach. Mater. 2011, 9, 295-315. [CrossRef]

43. Johnson, G.R.; Cook, W.H. A constitutive model and data for metals subjected to large strains, high strain rates and high temperatures. In Proceedings of the 7th International Symposium on Ballistics, The Hague, The Netherlands, 19-21 April 1983; Volume 21, pp. 541-547.

44. Zabel, A.; Rödder, T.; Tiffe, M. Material Testing and Chip Formation Simulation for Different Heat Treated Workpieces of 51CrV4 Steel. Procedia CIRP 2017, 58, 181-186. [CrossRef]

45. Hockett, J.E.; Sherby, O.D. Large strain deformation of polycrystalline metals at low homologous temperatures. J. Mech. Phys. Solids 1975, 23, 87-89. [CrossRef]

46. Saelzer, J.; Zabel, A.; Biermann, D. Experimental Analysis of the Friction Behaviour in Cutting. In Production at the Leading Edge of Technology, Proceedings of the 9th Congress of the German Academic Association for Production Technology (WGP), Hamburg, Germany, 30 September-2 October 2019; Springer: Berlin/Heidelberg, Germany, 2019; pp. 297-305.

47. Afrasiabi, M.; Klippel, H.; Roethlin, M.; Wegener, K. Parameter Identification of a Friction Model in Metal Cutting Simulations with GPU-Accelerated Meshfree Methods. In Proceedings of the 14th World Congress on Computational Mechanics, Paris, France, 19-24 July 2020; pp. 1-12.

48. Brookshaw, L. A method of calculating radiative heat diffusion in particle simulations. Publ. Astron. Soc. Aust. 1985, 6, 207-210. [CrossRef]

49. Monaghan, J.J. Smoothed particle hydrodynamics. Ann. Rev. Astron. Astrophys. 1992, 30, 543-574. [CrossRef]

50. Wendland, H. Piecewise polynomial, positive definite and compactly supported radial functions of minimal degree. Adv. Comput. Math. 1995, 4, 389-396. [CrossRef]

51. Monaghan, J.; Gingold, R. Shock simulation by the particle method SPH. J. Comput. Phys. 1983, 52, 374-389. [CrossRef]

52. Gray, J.; Monaghan, J.; Swift, R. SPH elastic dynamics. Comput. Methods Appl. Mech. Eng. 2001, 190, 6641-6662. [CrossRef]

53. Afrasiabi, M.; Roethlin, M.; Wegener, K. Thermal simulation in multiphase incompressible flows using coupled meshfree and particle level set methods. Comput. Methods Appl. Mech. Eng. 2018, 336, 667-694. [CrossRef]

54. Cleary, P.W.; Monaghan, J.J. Conduction modelling using smoothed particle hydrodynamics. J. Comput. Phys. 1999, 148, 227-264. [CrossRef]

55. Monaghan, J.J. Smoothed particle hydrodynamics. Rep. Prog. Phys. 2005, 68, 1703. [CrossRef]

56. Afrasiabi, M.; Roethlin, M.; Wegener, K. Contemporary Meshfree Methods for Three Dimensional Heat Conduction Problems. Arch. Comput. Methods Eng. 2020, 27, 1413-1447. [CrossRef]

57. Afrasiabi, M. Thermomechanical Simulation of Manufacturing Processes using GPU-Accelerated Particle Methods. Ph.D. Thesis, ETH Zurich, Zurich, Switzerland, 2020.

58. Ducobu, F.; Rivière-Lorphèvre, E.; Filippi, E. On the importance of the choice of the parameters of the Johnson-Cook constitutive model and their influence on the results of a Ti6Al4V orthogonal cutting model. Int. J. Mech. Sci. 2017, 122, 143-155. [CrossRef]

59. Sima, M.; Özel, T. Modified material constitutive models for serrated chip formation simulations and experimental validation in machining of titanium alloy Ti-6Al-4V. Int. J. Mach. Tools Manuf. 2010, 50, 943-960. [CrossRef]

60. Bahi, S.; Nouari, M.; Moufki, A.; El Mansori, M.; Molinari, A. A new friction law for sticking and sliding contacts in machining. Tribol. Int. 2011, 44, 764-771. [CrossRef] 